\title{
ÁC CẢM TIÊU DÙNG: TỔNG KẾT LÝ THUYẾT VÀ ĐỊNH HƯớNG NGHIÊN CỨU Ở VIỆT NAM
}

\author{
NGUYẼ̃N THÀNH LONG ${ }^{1}$, ĐẶNG HÙNG VŨ² \\ ${ }^{1}$ Nghiên cứu viên tụ do, ${ }^{2}$ Trường Đại học An Giang, Đại học Quốc gia Thành phố Hồ Chí Minh; \\ ngthanhlong61@gmail.com_dhvu@agu.edu.vn
}

Tóm tắt. Nghiên cứu này tổng kết lý thuyết, phân tích cấu trúc của khái niệm ác cảm tiêu dùng và đề xuất hướng nghiên cứu về ác cảm tiêu dùng tại Việt Nam. Các nghiên cứu được chọn là các bài nghiên cứu đã được bình duyệt trong các cơ sở dữ liệu điện tử ProQuest, Sciendirect, Springer được công bố trong khoảng thời gian từ 2007 đến 2019. Tổng kết được trình bày theo năm phân nhóm bao gồm: cấu trúc khái niệm, phân loại ác cảm, bối cảnh nghiên cứu, đo lường và đánh giá khái niệm ác cảm tiêu dùng. Tổng kết này cho thấy có hai mô hình có thể được dùng để đo lường ác cảm tiêu dùng; cần nghiên cứu xem dạng cấu trúc nào của khái niệm ác cảm là có giá trị cao hơn. Ác cảm tiêu dùng có thể bao gồm một hoặc vài thành phần sau: chiến tranh, quân sự, chính trị, kinh tế, tôn giáo, lịch sử và cá nhân. Ác cảm tiều dùng có ảnh hưởng tiêu cực đến sự sẵn lòng mua. Một số hướng nghiên cứu được đề xuất thực hiện trong bối cảnh của Việt Nam.

Từ khóa. Ác cảm tiêu dùng, chiến tranh, kinh tế, quân sự, sự sẵn lòng mua, thẩm định hàng hóa

\section{CONSUMER ANIMOSITY: A REVIEW AND FURTHER RESEARCH IN VIETNAM}

\begin{abstract}
This paper aims to review the literature on animosity, which aims at analyzing the structure of consumer animosity construct and finding research gaps for future research in Vietnam. Selected papers are from peer-reviewed journals on ProQuest, ScienceDirect, Springer database from 2007 to 2019. This literature review comprises five groups: construct structure, typologies, research context, measurement model and evaluation of consumer animosity. The review shows two possible measurement models of consumer animosity, the validity of which needs to be examined. Consumer animosity has one or more dimensions, such as war, military, politic, economic, religion and personal factors. It is revealed that consumer animosity has negative effect on buying intention. A number of issues are proposed for further research in the context of Vietnam.
\end{abstract}

Key words. consumer animosity, war, economic factors, military, buying willingness, commodity judgement

\section{GIỚI THIẸU}

Toàn cầu hóa diễn ra ngày càng mạnh mẽ vì hai nhân tố: (1) khoa học công nghệ phát triển mạnh mẽ và (2) rào cản thương mại và đầu tư dần được hạ thấp [1].đang được quan tâmNhờ sự phát triển và lan tỏa mạnh mẽ của công nghệ thông tin và liên lạc, chi phí vận tải và thông tin liên lạc giảm cũng trở thành động lực thúc đẩy toàn cầu hóa [2]. Nhờ vậy, hàng hóa lưu thông giữa các quốc gia trên thế giới ngày càng nhanh chóng và mạnh mẽ. Hàng hóa nội địa phải chịu sức cạnh tranh của các hàng hóa ngoại nhập; bên cạnh, hàng ngoại đến từ nhiều quốc gia khác nhau cũng phải chịu sự cạnh tranh lẫn nhau. Trong tình huống này, các nhà quản trị tiếp thị trong lẫn ngoài nước phải hiểu được hành vi người tiêu dùng nước sở tại trong tình huống để có các chiến lược, chiển thuật phù hợp mới có thể tồn tại và giành lợi thế cạnh tranh.

Một cách tổng quát, hành vi cá nhân có thể chịu ảnh hưởng của nhận thức, cảm xúc và chuẩn mực cá nhân/xã hội. Trong lĩnh vực nghiên cứu tiếp thị, ba nhân tố tác động đến ý định mua hàng ngoại của người tiêu dùng đang được quan tâm là: (1) tính vị chủng tiêu dùng (consumer ethnocentrism) là nhân tố chuẩn 
mực, (2) ác cảm tiêu dùng (animosity/consumer animosity) là nhân tố cảm xúc và (3) hình ảnh sản phẩmquốc gia (country-product image) [vd: 3, 4-6] là nhân tố nhận thức.

Bên cạnh giá, chất lượng sản phẩm phải là điều mà người tiêu dùng thẩm định trước khi ra quyết định mua. Nếu sản phẩm chưa quen thuộc, quốc gia xuất xứ (country-of-origin) của sản phẩm là tín hiệu để người tiêu dùng suy diễn ra chất lượng sản phẩm [Bilkey and Nes, 1982; Steenkamp, 1990, dẫn theo 7]. Cụ thể hơn, các nhà nghiên cứu hành vi tiêu dùng đã phát triển khái niệm hình ảnh sản phẩm-quốc gia, được Nagashima [1970:8, dẫn theo 8] định nghĩa là toàn bộ niềm tin của một người về sản phẩm của một quốc gia nào đó, thay cho khái niệm tổng quát quốc gia xuất xứ.

Việc mua hàng ngoại không chỉ dựa vào nhận thức duy lý về hình ảnh sản phẩm-quốc gia ở trên. Các quốc gia quan hệ với nhau không chỉ trong phạm vi kinh tế mà còn trong chính trị, quân sự, ngoại giao, văn hóa, tài nguyên thiên nhiên... Các quan hệ, biến cố song phương, đa phương đó có thể tạo ra cảm xúc tích cực hay tiêu cực của cá nhân quốc gia này đối với một quốc gia cụ thể khác. Ác cảm tiêu dùng được Klein, et al. (1998) [4] định nghĩa là sự thù ghét (cảm xúc tiêu cực) của người tiêu dùng đối với một quốc gia khác do xung đột hay mâu thuẫn trong quá khứ hay hiện tại. Ác cảm này có thể đến từ các nguyên nhân kinh tế, chính trị và tác động tiêu cực đến sự sẵn lòng mua hàng có xuất xứ từ quốc gia đó. Kết quả nghiên cứu Klein, et al. (1998) [4] khẳng định người tiêu dùng ở Nam Kinh không muốn mua hàng Nhật vì ác cảm từ cuộc thảm sát Nam Kinh năm 1937 đã mở đầu cho nhiều nghiên cứu tiếp sau. Có thể lấy ví dụ như: người Hy Lạp không muốn mua hàng Thổ Nhĩ Kỳ vì tranh chấp ở đảo Chypre [5]; người Pháp vì nhiều lý do kinh tế, chính trị, văn hóa, không sẵn lòng tiêu dùng hàng Hoa Kỳ [6].

Qua tin tức thời sự, có thể nhận ra các cuộc tẩy chay hàng ngoại vì ác cảm diễn ra ở một số quốc gia. Điển hình là Trung Quốc tẩy chay hàng Pháp vì Tổng thống Pháp dọa không đến dự khai mạc Olympic Bắc Kinh [9], các nước Hồi giáo và cả Đức, Pháp tẩy chay hàng Hoa Kỳ vì chiến tranh Iraq [10]. Người tiêu dùng Ân Độ tẩy chay hàng Trung Quốc vì Trung Quốc là quốc gia khiến Ấn Độ có mức thâm hụt thương mại lớn nhất; các chiến dịch tẩy chay hàng Trung Quốc của Ấn Độ còn xuất phát từ nguyên nhân tình cảm và lịch sử, do Trung Quốc ủng hộ Pakistan và thể hiện quan điểm không phù hợp với các lợi ích của Ấn Độ $[11,12]$. Năm 2017 , các doanh nghiệp sản xuất Hàn Quốc đối mặt với chiến dịch tẩy chay hàng hóa và dịch vụ Hàn Quốc ở Trung Quốc vì Seoul cho triển khai một hệ thống lá chắn tên lửa của Mỹ [13]. Người tiêu dùng Canada phản đối Tổng thống Donal Trump bằng cách tẩy chay hàng hóa của Hoa Kỳ [14]. Trong cuộc chiến tranh thương mại Trung Quốc và Hoa Kỳ, người sử dụng internet Trung Quốc kêu gọi tẩy chay các sản phẩm của Hoa Kỳ để phản ứng lại quyết định áp thuế đối với hàng Trung Quốc của Tổng thống Donald Trump [15].

Kể từ khi mở cửa, kinh tế Việt Nam không ngừng tăng trưởng. Năm 2001, kim ngạch xuất, nhập khẩu chỉ là 15,2 và 16,2 tỉ USD thì đến năm 2011 kim ngạch xuất, nhập khẩu đã lên đến 96,9 và 106,7 tỉ USD; đến năm 2017 là 214,0 và 211,1 tỷ USD. Các quốc gia có lượng hàng nhập khẩu lớn vào Việt Nam trong năm 2018 là Hàn Quốc, Hoa Kỳ, Trung Quốc, Nhật, Đài Loan, Thái, Malaysia [16] . Người tiêu dùng Việt Nam giờ đây có thể dễ dàng tìm thấy đủ loại hàng ngoại nhập trên quầy kệ các siêu thị, trung tâm mua sắm, cửa hàng tạp phẩm và cả ở các sạp chợ. Dù có vài tín hiệu lạc quan, nhưng hàng Việt Nam nhìn chung được cho là thất thế và chịu áp lực cạnh tranh rất lớn ngay trên thị trường quê nhà, dù được cuộc vận động "Người Việt dùng hàng Việt" tiếp sức trong những năm gần đây [17-20].

Về lịch sử, Việt Nam có nhiều cuộc chiến tranh giành độc lập với các quốc gia như Trung Quốc - nhà nước phong kiến nhiều lần xâm chiếm Việt Nam, Nhật - quân đội fascist chiếm Việt Nam từ tay người Pháp rồi gây ra nạn đói 1945, Hoa Kỳ - nước tiển hành cuộc chiến tranh Việt Nam kết thúc năm 1975, Hàn Quốc - đồng minh của Hoa Kỳ đã cử quân đội tham chiến trực tiếp tại Việt Nam... Gần đây, các vụ kiện bán phá giá và phán quyết áp thuế của Bộ Thương mại Hoa Kỳ với cá da trơn hay tranh chấp lãnh thổ trên biển Đông với Trung Quốc cũng là các sự kiện đáng chú ý. Tất cả sự kiện lịch sử, đương đại trên đều có thể tạo nên cảm xúc tiêu cực ở người tiêu dùng.

Nghiên cứu ác cảm trong hành vi tiêu dùng hàng ngoại đã được thực hiện ở nhiều nơi trên thế giới, tuy nhiên, vẫn còn sự không nhất quán trong cấu trúc của khái niệm ác cảm và tác động của nó đến thẩm định sản phẩm. Riêng ở Việt Nam, nghiên cứu chủ đề này là hiếm hoi. Chưa tìm thấy bài báo nghiên cứu nào về chủ đề, phạm vi này trên cơ sở dữ liệu Proquest và tài liệu khoa học và công nghệ Việt Nam. Gần đây, một vài nghiên cứu liên quan liên quan gần, ví dụ như Võ Thị Quý and Cao Quốc Việt (2015) [21], khám phá các yếu tố tác động đến hành vi tẩy chay của người tiêu dùng. Luận án tiến sĩ của nghiên cứu sinh Đặng Thị Kim Thoa (2017) [22] sử dụng định kiến mang tính lịch sử với Trung Quốc và Thái Lan làm 
biến điều tiết trong mô hình nghiên cứu các nhân tố ảnh hưởng đến sự sẵn lòng mua hàng may mặc nội địa của người tiêu dùng Việt Nam.

Mặt khác, Việt Nam là một quốc gia đang phát triển, trình độ công nghệ chưa cao, quan hệ với các nước phát triển (Hoa Kỳ, Nhật) và các nước mới nổi (Trung Quốc, Hàn Quốc) không chỉ có xung đột mà còn có hợp tác, nhận hỗ trợ. Người Việt Nam lại được cho là yêu nước và có tinh thần cởi mở với các quốc gia khác. Do vậy, câu hỏi có tồn tại ác cảm tiêu dùng với quốc gia nào đó hay không, vai trò của ác cảm này trong hành vi tiêu dùng hàng ngoại của người Việt là cần và đáng được trả lời.

Bài báo này tổng kết các nghiên cứu về ác cảm tiêu dùng, đề xuất một vài mô hình nghiên cứu và định hướng nghiên cứu. Trước hết, bài báo trình bày khái niệm, nguồn gốc, phân loại ác cảm và ác cảm tiêu dùng. Một số nghiên cứu về ác cảm tiêu dùng được tổng kết tập trung vào các tình huống nghiên cứu, cách tiếp cận và đánh giá khái niệm. Trên cơ sở các nghiên cứu trước, bài báo đề xuất các mô hình nghiên cứu và định hướng nghiên cứu tiếp theo về ác cảm tiêu dùng. Bài báo góp phần vào khối tri thức tiếp thị qua việc phân tích cấu trúc của khái niệm ác cảm tiêu dùng, hiểu biết thêm về các tiền tố tâm lý xã hội của khái niệm này.

\section{PHƯƠNG PHÁP NGHIÊN CÚU}

Nghiên cứu này nhằm phân tích các nghiên cứu trước đây về ác cảm tiêu dùng trong 20 năm qua. Các nghiên cứu trước đây được chọn chủ yếu từ các cơ sở dữ liệu điện tử ProQuest, ScienceDirect, Springer. Đây là các bài nghiên cứu đã được bình duyệt được công bố trong khoảng thời gian từ 2007 đến 2019. Từ khóa để tìm kiếm là animosity và consumer animosity.

Dữ liệu được phân tích phân tích nội dung theo: (1) cấu trúc khái niệm, (2) phân loại ác cảm, (3) bối cảnh nghiên cứu, (4) đo lường và (5) đánh giá khái niệm ác cảm tiêu dùng. Nghiên cứu này sẽ phân tích những vấn đề tồn tại về cấu trúc và đo lường khái niệm ác cảm tiêu dùng. Thông qua lược khảo các nghiên cứu thực nghiệm, nghiên cứu này tổng kết các nguyên nhân được cho là gây ra cảm tiêu dùng. Kết quả lược khảo là những đề xuất kiểm định cả mô hình cấu trúc khái niệm ác cảm tiêu dùng và xác định một số lĩnh vực cần nghiên cứu tiếp theo.

Các nghiên cứu lý thuyết và thực tiễn về ác cảm được trình bày theo chiều thời gian với các dấu mốc đáng chú ý. Trước hết, 04 nghiên cứu khai sinh và củng cổ khái niệm của Jill Gabrielle Klein cùng các cộng sự trong các năm 1998, 1999, 2002, 2005 được giới thiệu. Phần tiếp theo là quan điểm phân loại ác cảm của Jung, et al. (2002) [23], Ang, et al. (2004) [24] và kết quả tổng lược 15 nghiên cứu ác cảm và phê phán cấu trúc đo lường khái niệm này của Riefler and Diamantopoulos (2007) [25].

Sau tổng lược và phể phán của Riefler and Diamantopoulos (2007) [25], tiếp tục có nhiều nghiên cứu về ác cảm được công bố. Theo ProQuest, từ 2009-2018, đã có 1.122 bài báo nghiên cứu liên quan đến từ khóa consumer animosity, product judgment. Trải qua 10 năm, Shoham, et al. (2016) [26] có một tổng lược phân tích các nghiên cứu thực nghiệm đánh giá tác động của ác cảm, các mô hình lý thuyết đã được kiểm định và tổng hợp các tác động của ác cảm đển các biến marketing như sự đánh giá chất lượng sản sự sẵn lòng mua và thực mua. Nghiên cứu này trình bày kết quả tổng kết 20 nghiên cứu được chon lọc (xem Bảng 4 và Bảng 5), tập trung phân tích (1) tình huống và nguồn gốc ác cảm, (2) phân loại, cấu trúc đo lường và cách tiếp cận khái niệm ác cảm, và (3) giá trị khái niệm. Phần tổng lược 20 nghiên cứu ác cảm trong 20 năm qua từ 2007 đến 2019 trình bày các nhận xét tổng hợp và phê phán là cơ sở để đề xuất một số định hướng nghiên cứu về ác cảm tại Việt Nam.

\section{CƠ SỞ LÝ THUYẾT}

\subsection{Khái niệm ác cảm tiêu dùng}

Lần đầu tiên vào năm 1998, khái niệm ác cảm (animosity) trong mô hình người tiêu dùng mua hàng nước ngoài được Jill Gabrielle Klein và các cộng sự giới thiệu qua một nghiên cứu lý thuyết kết hợp kiểm định trên thực tiễn. Klein, et al. (1998) [4] chỉ ra rằng các nghiên cứu trước đây về hành vi của người tiêu dùng thời toàn cầu hóa thường tập trung vào ảnh hưởng bởi các tín hiệu chất lượng của sản phẩm gắn liền với quốc gia xuất xứ sản phẩm đó (country of origin - $\mathrm{COO}$ ) và/hoặc ảnh hưởng của đạo đức, trách nhiệm như tính vị chủng tiêu dùng (consumer ethnocentrism). Trong khi đó, sự căng thẳng, xung đột lịch sử giữa 
các quốc gia có thể gây ra các tình cảm tiêu cực ở khách hàng đối với một quốc gia cụ thể, tình cảm này lại tác động đến hành vi mua hàng có xuất xứ từ quốc gia đó. Vấn đề này là một khoảng trống nghiên cứu.

Theo Klein, et al. (1998) [4], “... ác cảm là cảm xúc tiêu cực tồn đọng liên quan đến các biến cố quân sự, chính trị hoặc kinh tế, tình cảm này sẽ tác động lên hành vi mua của người tiêu dùng trong thị trường quốc tế”. Người tiêu dùng có thể từ chối mua hàng nhập khẩu từ một quốc gia nào đó không chỉ vì chất lượng, giá cả mà vì mà họ cho rằng quốc gia đó đã có việc làm xấu, khó thể tha thứ.

Kể từ đây, Jill Gabrielle Klein và các cộng sự đã tiến hành 04 nghiên cứu lý thuyết và thực tiễn về ác cảm tiêu dùng ở các quốc gia và tình huống khác nhau, nhằm (1) xác định cấu trúc khái niệm, (2) chỉ ra các tiền tố và kiểm định ảnh hưởng (hệ quả) của nó đối với hành vi mua (xem phân tích ở Bảng 1 ). Có thể đưa ra các nhận định sau:

Nguồn gốc của ác cảm có thể xuất phát từ các sự kiện lịch sử gắn liền với các cuộc chiến tranh (vd: thế chiến thứ II) hoặc các vấn đề đương đại thể hiện qua quan hệ kinh tế song phương (cạnh tranh, công bằng thương mại giữa Hoa Kỳ-Nhật, Trung Quốc-Nhật), hay chính sách an ninh (thử hạt nhân của Pháp ở châu Đại Dương). Quốc gia mục tiêu đều là cường quốc kinh tế, quân sự (Nhật, Pháp).

Về cấu trúc, ác cảm được tiếp cận theo 02 kiểu cấu trúc đa hướng khác nhau: (1) khái niệm ẩn, kiểu phản ánh (reflective) bậc II, có 2 thành phần bậc I là ác cảm chiến tranh (war animosity) - 3 biến quan sát, ác cảm kinh tế (economic animosity) - 5 biến quan sát và 01 biến quan sát là ác cảm nói chung [4] và ; (2) khái niệm ẩn -3 biến quan sát, kiểu phản ánh bậc II, có 2 thành phần bậc I là ác cảm chiến tranh (war animosity), ác cảm kinh tế (economic animosity), mỗi thành phần có 3 biến quan sát [27]. Hai nghiên cứu còn lại $[28,29]$ không tiếp cận ác cảm như khái niệm đa hướng (04 biến quan sát), chỉ sử dụng proxy (01 biến quan sát) hoặc ác cảm tổng quát (đơn hướng) để phục vụ mục đích đặc trưng.

Nhìn chung, các nghiên cứu trên khẳng định được ác cảm tác động tiêu cực đến sự sẵn lòng mua (willingness to buy) hàng từ quốc gia mục tiêu và không gây ảnh hưởng gì đến thẩm định hàng hóa (product judgment). Tuy nhiên, trong một nghiên cứu thái độ đối với hàng Pháp của người Úc trước và sau vụ thử hạt nhân của Pháp [29], kết quả cho thấy sau khi Pháp ngưng thử nghiệm, ác cảm giảm xuống nhưng lại tác động tiêu cực đến thẩm định hàng hóa, khác với kết quả phân tích trước vụ thử. Kết quả này tương tự như nghiên cứu ác cảm giữa Trung Quốc và Nhật Bản của Lee, et al. (2017) [30]. Điều này được giải thích theo lý thuyết về ký ức, theo đó ác cảm được cho là ký ức thời kỳ (episodic memory).

Bảng 1: Phân tích các nghiên cưu khái niệm ác cảm tiêu dùng

\begin{tabular}{|c|c|c|}
\hline Nguồn & Cấu trúc & Tác động/Hệ quả \& Tiền tố \\
\hline $\begin{array}{l}\text { Klein, et al. } \\
\text { (1998) [4] }\end{array}$ & $\begin{array}{l}\text { Ác cảm là khái niệm ẩn (latent), } \\
\text { có cấu trúc bậc II, dạng phản } \\
\text { ánh, gồm } 2 \text { thành phần bậc I: (1) } \\
\text { Ác cảm do chiến tranh (03 mục } \\
\text { đo); (2) Ác cảm do kinh tế (05 } \\
\text { mục đo đo và (3) một biến quan } \\
\text { sát thể hiện ác cảm tồng quát }\end{array}$ & $\begin{array}{l}\text { Ác cảm không tác động đến thẩm định hàng hóa } \\
\text { nhưng tác động âm đến sự sẵn lòng mua }\end{array}$ \\
\hline $\begin{array}{l}\text { Klein and } \\
\text { Ettenson } \\
\text { (1999) [28] }\end{array}$ & $\begin{array}{l}\text { Dùng proxy là } 1 \text { câu hỏi trong } \\
\text { cuộc khảo sát bầu cử quốc gia } \\
\text { năm } 1992 \text { thay cho khái niệm ác } \\
\text { cảm. Kiểm định proxy bằng } \\
\text { phân tích tương quan với ác cảm } \\
\text { từ kinh tế qua dữ liệu điều tra cỡ } \\
\text { mẫu nhỏ }(\mathrm{N}=250)\end{array}$ & $\begin{array}{l}\text {-Tính vị chủng tiêu dùng tác động đến cả thẩm } \\
\text { định vă săn lòng mua hàng ngoại, ác cảm chỉ tác } \\
\text { động đến sự sắn lòng mua. } \\
\text { - Tiền tố nhân khẩu học (demographic) và } \\
\text { psychographic (tâm lý đồ) của tính vị chủng tiêu } \\
\text { dùng và ác cảm là khác nhau }\end{array}$ \\
\hline
\end{tabular}


NGHIÊN CÚUU Ở VIÊTT NAM

\begin{tabular}{|c|c|c|}
\hline Nguồn & Cấu trúc & Tác động/Hệ quả \& Tiền tố \\
\hline $\begin{array}{l}\text { Klein }(2002) \\
{[27]}\end{array}$ & $\begin{array}{l}\text { Ác cảm là khái niệm ẩn ( } 03 \text { mục } \\
\text { đo), có cấu trúc bậc II, dạng } \\
\text { phản ánh, gồm } 2 \text { thành phần bậc } \\
\text { I: (1) Ác cảm do chiến tranh ( } 03 \\
\text { mục đo }) \text {; (2) Ác cảm do kinh tế } \\
\text { (03 mục đo) }\end{array}$ & $\begin{array}{l}\text {-Ác cảm tác động âm đến chọn lựa hàng Nhật so } \\
\text { với Hàn Quốc nhưng không tác động đển chọn lựa } \\
\text { hàng Nhật so với Hoa Kỳ. } \\
\text {-Tính vị chủng tiêu dùng tác động âm đến chọn lựa } \\
\text { hàng Nhật so với Hoa Kỳ nhưng không tác động } \\
\text { đến chọn lựa hàng Nhật so với Hàn Quốc. } \\
\text {-Ác cảm không tác động đến thẩm định hàng hóa } \\
\text { Tuồi (đồng biển) } \\
\text {-Giới (Nam có ác cảm cao hơn nữ) }\end{array}$ \\
\hline $\begin{array}{l}\text { Ettenson and } \\
\text { Klein (2005) } \\
\text { [29] }\end{array}$ & $\begin{array}{l}\text { Ác cảm là khái niệm đơn hướng } \\
\text { (04 mục đo) }\end{array}$ & $\begin{array}{l}\text { Trước: Ác cảm tác động âm đến sẵn lòng mua và } \\
\text { không tác động đến thẩm định hàng hóa } \\
\text { Sau: Âc cảm vẫn tác động âm đến sẵn lòng mua và } \\
\text { cũng tác động âm đến thẩm định hàng hóa. } \\
\text { Ác cảm giảm cường độ, sự sằn lòng mua được } \\
\text { nâng lên }\end{array}$ \\
\hline
\end{tabular}

Bảng 2: Tiền tố của ác cảm và tính vị chủng tiêu dùng theo Klein and Ettenson (1999) [28]

\begin{tabular}{|c|c|c|c|}
\hline Tiền tố & & $\begin{array}{l}\text { Tính vị chủng } \\
\text { tiêu dùng }\end{array}$ & Ác cảm \\
\hline \multirow{4}{*}{$\begin{array}{l}\text { Đị́a vị kinh } \\
\text { tê-xã hội }\end{array}$} & Học vấn & - & \\
\hline & Thu nhập & - & \\
\hline & Nghề nghiệp & $\mathrm{X}$ & \\
\hline & Thành viên nghiệp đoàn & $\mathrm{X}$ & \\
\hline \multirow{4}{*}{ Tâm lý đồ } & Niềm tin lạc quan (cá nhân) & - & \\
\hline & Niềm tin lạc quan (quốc gia) & - & \\
\hline & Định kiến đối với chủng người (Á) & & - \\
\hline & Chủ nghĩa yêu nước & + & + \\
\hline \multirow{3}{*}{$\begin{array}{l}\text { Nhân khẩu } \\
\text { học }\end{array}$} & Tuổi & & + \\
\hline & Chủng tộc & & $X$ \\
\hline & Giới & Nữ $>$ Nam & Nam $>N \tilde{u}$ \\
\hline
\end{tabular}

Ghi chú: - : tuoong quan âm, + : tuoong quan dưong, $x$ : có quan hẹ

Tính vị chủng (ethnocentrism) là một khái niệm được khai sinh từ đầu thế kỷ, được Sumner dẫn theo Sharma, et al. (1995) [31] định nghĩa là "cách nhìn các sụ vật của một người mà cộng đồng của họ đuợc cho là trung tâm, là mẫu mưc, là thước đo của tất cả sụ vật chung quanh. mỗi công đồng đều nuôi duỡng niềm tụ hào, tư tôn, ho tán dương nhũng người trong cộng đồng và xem thường người ngoài cộng đồng đó". Sharma, et al. (1995) [31] tổng kết các đặc trưng của tính vị chủng tiêu dùng như sau: (1) là kết quả của lòng yêu nước và e ngại mất kiểm soát lợi ích kinh tế quốc gia do nhập khẩu, (2) làm xuất hiện tâm niệm không mua hàng ngoại vì hành vi này bị đánh giá đạo đức là thiếu trách nhiệm, không yêu nước, không đúng đắn; (3) từ đó, dẫn đến định kiến chống nhập khẩu. Hệ quả tính vị chủng tiêu dùng là sự thiên vị: đánh giá cao hàng nội, đánh giá thấp hàng ngoại và không sẵn lòng mua hàng ngoại trong khi luôn ưu tiên quan tâm hàng nội. Không những vậy, mua hàng nội như một bổn phận.

Ác cảm là khác biệt với tính vị chủng tiêu dùng về nội hàm, hệ quả và cả tiền tố. Tính vị chủng tiêu dùng mang bản chất đạo đức, nghĩa vụ đối với cộng đồng của một cá nhân; do đó, nó ảnh hưởng tiêu cực đến thái độ tiêu dùng của cá nhân qua đánh giá thấp và không sẵn lòng mua hàng ngoại nói chung; họ chỉ mua hàng ngoại khi không có hàng nội. Trong khi đó, ác cảm mang bản chất cảm xúc, hướng người tiêu 
dùng đến tránh dùng hoặc tẩy chay (boycott) hàng của một quốc gia cụ thể để chọn hàng từ quốc gia khác: chẳng hạn người Hoa Kỳ có xu hướng chọn ô tô Hàn Quốc thay cho Nhật, vì có ác cảm cao với Nhật [27]. Các tiền tố của hai khái niệm này được tóm lược ở Bảng 2 . Tính vị chủng được cho là tiền tố của ác cảm [30]. Trong khi Marinković (2017) [32] cho rằng ác cảm và lòng yêu nước là hai tiền tố của tính vị chủng;

Như vậy, các nghiên cứu khởi đầu của Klein, J.G. cùng các cộng sự đã đưa một khái niệm tâm lý xã hội mới vào hành vi tiêu dùng hàng ngoại. Các tiền tố, hệ quả và giá trị khái niệm đã được kiểm định qua dữ liệu thị trường. Dựa vào đây, nhiều nghiên cứu tiếp sau được thực hiện, trong đó, đáng chú ý là phân loại ác cảm của Jung, et al. (2002) [23]; Ang, et al. (2004) [24] và tổng kết 15 nghiên cứu thực tiễn của Riefler and Diamantopoulos [25] phê phán cấu trúc chưa hợp lý và cách xây dựng thang đo mang tính chủ quan của khái niệm ác cảm.

Các nghiên cứu tiếp sau còn dùng thuật ngữ ác cảm tiêu dùng (consumer animosity) với cùng nội hàm như ác cảm (animosity). Trong bài viểt này, hai thuật ngữ có thể cùng được sử dụng để chỉ một khái niệm.

\subsection{Phân loại ác cảm}

Jung, et al. (2002) [23] cho rằng ác cảm là thái độ thù địch (hostility attitude) gồm hai thành phần cảm xúc (emotion): giận, khinh miệt, chán ghét và niềm tin (belief): hoài nghi, ngờ vực đối với các nhóm ngoài quốc gia. Ác cảm là một khái niệm động, được sinh thành và cập nhật liên tục và từ nhiều nguồn gốc, sự kiện và kinh nghiệm khác nhau và đặc trưng của chúng còn phục thuộc vào phạm vi biểu hiện. Jung, et al. (2002) [23] đưa ra 2 thứ nguyên (dimension) để phân loại ác cảm như sau:

\subsection{1 Ác cảm tình huống và kiên định (situational vs. stable animosity)}

Ác cảm tình huống là cảm xúc thù hằn gắn với một hoàn cảnh, sự kiện, tình tiết cụ thể, nắm được. Với một quốc gia, cảm xúc này có thể hình thành từ các hành động khiêu khích thực tế hoặc cảm nhận có thể dẫn đến thảm họa hoặc thảm họa đã diễn ra trên thực tế, chẳng hạn khủng hoảng kinh tế châu Á cuối thế kỷ 20 được quy kết cho nước Hoa Kỳ, dẫn đến ác cảm với nước Hoa Kỳ. Lưu ý rằng, ác cảm này cũng có thể xuất phát từ bản tính của một cá nhân.

Ác cảm kiên định là cảm xúc thù hận tích lũy qua nhiều năm bởi những biến cố chính trị, quân sự, kinh tế giữa hai quốc gia. Cảm xúc này tuy bền nhưng không mang tính tự nhiên, cố hữu và gần như không có vai trò của cá tính. Nó được hình thành từ lũy kế cảm xúc từ nhiều sự kiện khác nhau tích hợp lại. Nỗi $\mathrm{e}$ sợ Liên Xô của người Hoa Kỳ hình thành từ các xung đột thời Chiến tranh Lạnh là một ví dụ.

Ác cảm tình huống liên quan đến một quốc gia nào đó có thể tiến hóa để trở trở thành ác cảm kiên định trong một cá nhân khi bộ nhớ ghi các sự kiện và cảm xúc liên quan trong não, chúng được gợi lại và củng cố, tích lũy thêm khi có biến cố thực tiễn liên quan xảy ra và dần nhập nội để trở thành dạng kiên định.

\subsection{2 Ác ảm cá nhân và ác cảm quốc gia (national vs. personal animosity)}

Ác cảm còn được đặc trưng bằng phạm vi biểu thị là cá nhân hay quốc gia, hàm nghĩa mức độ tác động cảm nhận được từ một quốc gia khác đến riêng một cá nhân hay cả quốc gia của cá nhân đó. Ở tầm vĩ mô, ác cảm quốc gia là cảm xúc phẫn nộ của cá nhân xuất phát từ hệ quả đã xảy ra hay nguy cơ đe dọa mà đất nước của cá nhân đó phải chịu đựng do các hành động của quốc gia khác. Các sự kiện này thường liên quan đến trạng thái kinh tế, vị thế, sức cạnh tranh và chủ quyền ở cấp độ quốc gia. Chẳng hạn, người Đài Loan có ác cảm với Trung Quốc lục địa vì cảm thấy bị đe dọa quân sự, ngược lại người Trung Quốc có ác cảm với Đài Loan vì đã đơn phương tuyên bố độc lập khỏi Trung Quốc.

Ở tầm vi mô, ác cảm cá nhân là cũng là cảm xúc phẫn nộ của cá nhân đối với quốc gia khác nhưng hình thành từ trải nghiệm tiêu cực mà chính cá nhân thu được đối với quốc gia đó hoặc con người thuộc quốc gia đó. Về mặt tâm lý, khi một người cảm thấy mình bị thua thiệt, chịu bẽ mặt, họ có xu hướng căm ghét đối tượng mà họ cho là chủ mưu và ác cảm càng tăng khi sự việc được cho là cố tình, sai trái.

Jung, et al. (2002) [23] đã kiểm định phân loại này bằng nghiên cứu thực tiễn về ác cảm của người dân 5 quốc gia: Indonesia, Hàn Quốc, Malaysia, Singapore và Thái Lan đối với hai quốc gia: một là, Nhật - với sự kiện lịch sử bằng sự chiếm đóng 05 quốc gia đó trong Thế chiến II; hai là, Hoa Kỳ - với trách nhiệm cáo buộc trong khủng hoàng kinh tế châu Á. Kết quả phân tích cho thấy bốn khái niệm ác cảm có cấu trúc bậc I, là đạt độ tin cậy và giá trị trị qua kiểm định thang đo bằng CFA. 
Ở một nghiên cứu lập lại (có mở rộng áp dụng lý thuyết quy kết) tiếp theo, với cùng cách thức, phạm vi lấy mẫu và chủ đề như Jung, et al. (2002) [23], Ang, et al. (2004) [24] một lần nữa xác định giá trị của phân loại trên qua đo lường độ tin cậy Cronbach Alpha.

Hai thứ nguyên trên là cơ sở cho một phân loại ác cảm theo ma trận 2x2 trong Bảng 3.

Bảng 3: Phân loại ác cảm

Phạm vi

Quốc gia

Cá nhân

Ác cảm kiên định quốc gia: hình thành từ các sự kiện lịch sử cấp quốc gia, qua thời gian, trở thành xu hướng phổ biến
Ác cảm kiên định cá nhân: cũng hình thành từ các sự kiện lịch sử, nhưng chỉ diễn ra trong phạm vi cá nhân

Nguồn

\section{Tình huống}

Ác cảm tình huống quốc gia: hình thành từ các sự kiện cụ thể đương đại gây hệ quả xấu ở cấp quốc gia
Ác cảm tình huống cá nhân: hình thành tình huống cụ thể tạo ra các hệ quả xấu ở mức cá nhân (xúc phạm, khó khăn)

Nguồn: Tổng hợp tù̀ các nghiên cứu của Jung, et al. (2002) [23] và Ang, et al. (2004) [24]

\subsubsection{Mở rộng phạm vi ác cảm tiêu dùng và phê phán cách tiếp cận, xác lập cấu trúc khái niệm.}

Riefler and Diamantopoulos (2007) [25] đã tiến hành tổng kết 15 nghiên cứu thực tiễn về ác cảm trong hành vi tiêu dùng hàng ngoại trong bối cảnh toàn cầu hóa và sự căng thẳng song phương giữa các quốc gia diễn ra khắp nơi. Các học giả này chia các nghiên cứu trên thành 3 nhóm: (1) nguyên thủy: khởi tạo khái niệm: gồm 02 nghiên cứu của Klein, et al. (1998) [4] và Klein and Ettenson (1999) [28] (vừa đề cập ở mục trên), (2) lập lại: nhằm kiểm định ở các tình huống khác nhau: 06 nghiên cứu và (3) mở rộng: làm rõ, làm tinh hoặc mở rộng phạm vi áp dụng của ác cảm: 07 nghiên cứu.

Kết quả tổng lược cho thấy sự nhất quán trong tác động tiêu cực của ác cảm đến sự sẵn lòng mua hàng của quốc gia mục tiêu, chỉ trong 03 trường hợp, không tìm thấy tác động này nhưng lại bộc lộ tác động tiêu cực đến thẩm định hàng hóa. Nguồn gốc sinh ác cảm được mở rộng, không chỉ từ chiến tranh, kinh tế mà còn từ tranh chấp lãnh thổ, ngoại giao, chính trị, cá nhân lãnh đạo quốc gia.... Phạm vi xuất xứ hàng hóa cũng mở rộng, ác cảm không chỉ hướng đến các quốc gia mục tiêu mà còn có thể hướng đến các vùng trong một quốc gia (vd: miền Bắc và Nam nước Hoa Kỳ, vùng Đông và Tây nước Đức...).

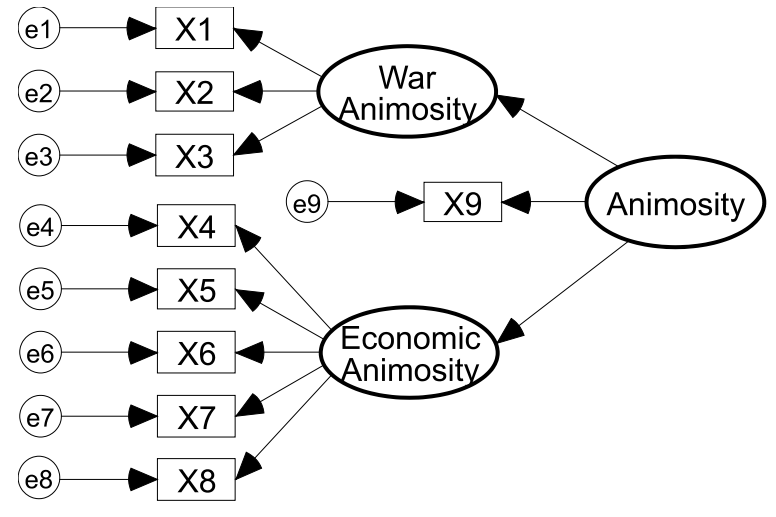

(a)

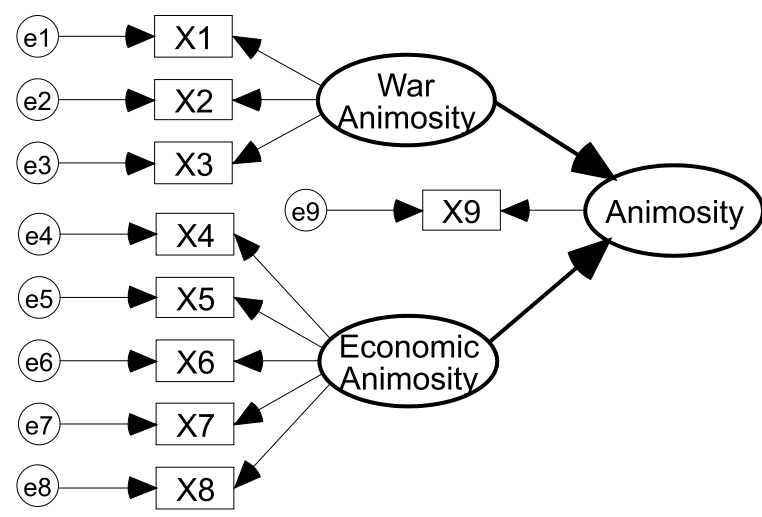

(b)

Hình 1: Mô hình đo lương ác cảm của Klein, et al. (1998) [4] và đề xuất hiệu chỉnh của Riefler and Diamantopoulos (2007) [25] 
X1: Tôi giận người Nhật

X2: Tôi không tha thứ cho Nhật về thảm sát Nam Kinh

X3: Nhật phải bị trùng phạt vì điè̀u đã làm ở Nam Kinh

X4: Nhật không là đối tác tin cậy

X5: Nhật muốn chiếm thế lục kinh tế trước Trung Quốc

X6: Nhật đang giành lợi thế của Trung Quốc

X7: Nhật làm ăn không nghiêm chỉnh ở Trung Quốc

X8: Nhật có quá nhiều ảnh hưởng kinh tế ở Trung Quốc

X9: Tôi không thich Nhật

Về cấu trúc và đo lường khái niệm, Riefler and Diamantopoulos (2007) [25] đưa ra các phê phán quan trọng sau đây:

Mô hình đo lường. Ác cảm nguyên thủy của Klein, et al. (1998) [4] là khái niệm ẩn, bậc II, dạng phản ánh với 2 thành phần bậc I dạng phản ánh: ác cảm do chiến tranh (03 biến quan sát), ác cảm do kinh tế (05 biến quan sát) và 1 biến quan sát ác cảm tổng quát (Hình 1a). Về nội dung, theo chính định nghĩa của Klein, et al. (1998) [4], ác cảm là một tình cảm xuất phát từ các sự kiện quá khứ hoặc đương đại, do vậy, cấu trúc dạng phản ánh là không tương thích với định nghĩa. Thay vào đó, cấu trúc tạo sinh (formative) là phù hợp hơn: hai thành phần ác cảm do chiến tranh và kinh tế vẫn có cấu trúc phản ánh nhưng tạo sinh ra ác cảm tổng hợp (Hình 1b)

Phát triển mục đo. Klein, et al. (1998) [4] đã ấn định trước quốc gia mục tiêu là và tình huống gây ác cảm (Nhật với cuộc thảm sát Nam Kinh) trước khi thực hiện nghiên cứu chính thức. Sự thiếu vắng một nghiên cứu khám phá có thể chưa cho thấy hết các nguyên nhân (ngoài chiến tranh, kinh tế) gây ra ác cảm đối với các quốc gia mục tiêu (không chỉ một quốc gia ấn định sẵn) ảnh hưởng nhất định đển giá trị khái niệm. Hơn nữa, ác cảm phải có nguyên nhân từ các sự kiện đặc tả, do đó, các biến quan sát được khái quát hóa là điều cần xem xét lại.

Riefler and Diamantopoulos (2007) [25] đề xuất cách tiếp cận ba bước cho nghiên cứu khám phá ác cảm như sau: (1) xác định các quốc gia mục tiêu, (2) làm rõ các nguyên nhân dẫn đển ác cảm, (3) đo lường tầm quan trọng của từng nguyên nhân tương thích với mô hình đa mục đo - đa nguyên nhân (multiple indicators- multiple causes (MIMIC)) để đo lường ác cảm như Hình 2. 


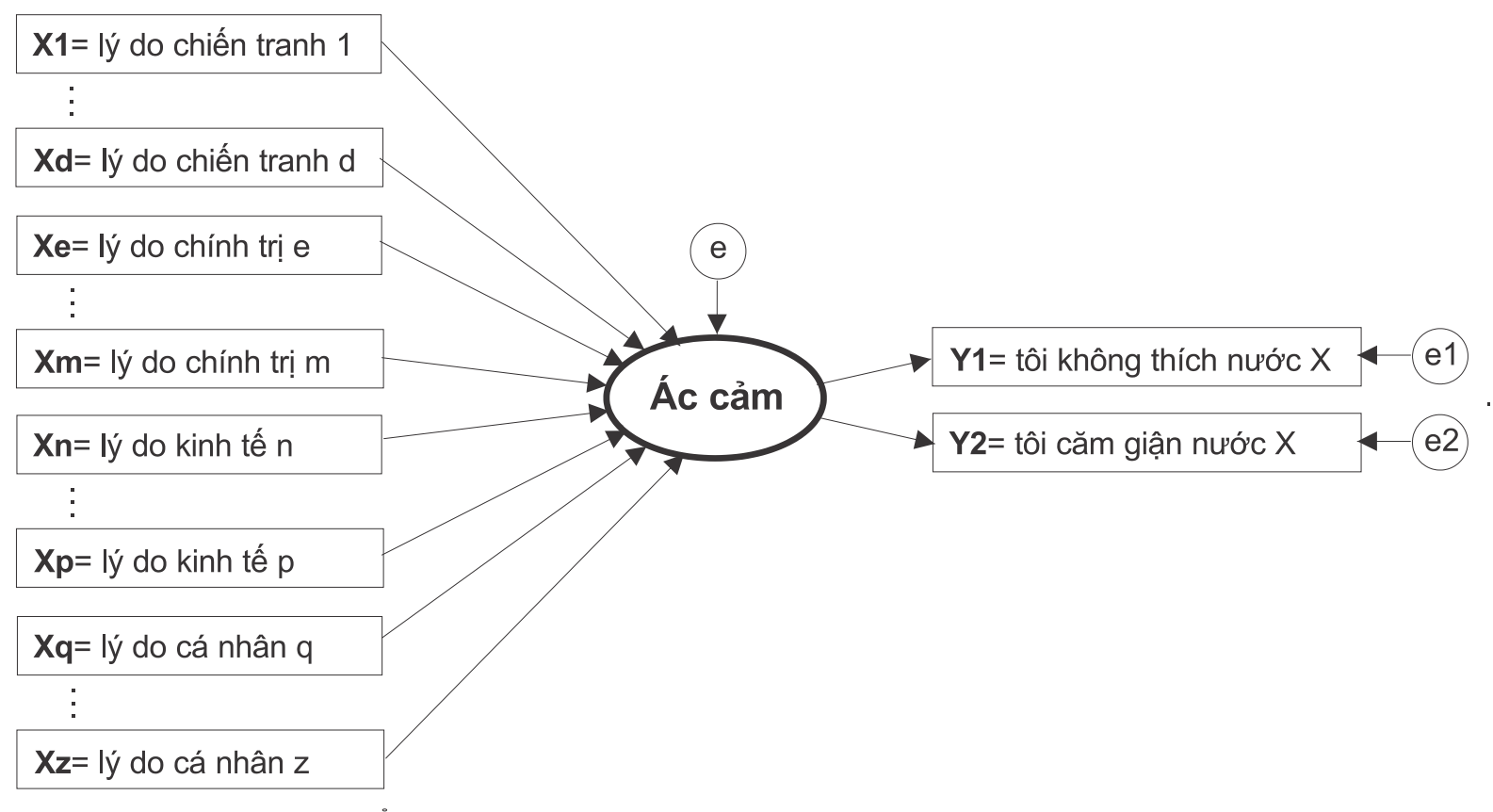

Hình 2: Mô hình MIMIC của ác cảm theo Riefler and Diamantopoulos (2007) [25]

\subsection{Tình huống và nguồn gốc ác cảm}

Các nghiên cứu ác cảm thực hiện ở nhiều nước sở tại ở các châu lục khác nhau, từ cường quốc hàng đầu, đã phát triển ở Âu, Hoa Kỳ (Hoa Kỳ, Pháp, Đức, Tây Ban Nha, Hy Lạp, Ukraina) đến các con rồng châu Á (Hàn Quốc, Đài Loan, Trung Quốc, Singapore), các quốc gia Trung, Cận Đông (Kuwait, Israel) hay các quốc gia đang phát triển (Thái Lan, Indonesia, Malaysia). Trong khi đó, nước mục tiêu hầu hết tập trung vào cường quốc kinh tế hoặc quân sự, có vị thế cao hơn nước sở tại như Hoa Kỳ, Nhật, Nga, Anh, Ý, Đan Mạch, Trung Quốc...

Chiến tranh là nguyên nhân chính của ác cảm, trong đó, có các xung đột lịch sử cổ đại (đế chế Ottoman), hiện đại (Thế chiến II, mà Nhật là nước mục tiêu hàng đầu) và các xung đột hoặc đối đầu quân sự đương đại (chiến tranh Việt Nam, tranh chấp lãnh thổ Hy Lạp - Thổ Nhĩ Kỳ). Kinh tế là tiếp tục nguyên nhân đứng thứ hai, thường được đề cập như cảm nhận về cạnh tranh kinh tế không công bằng mà nước sở tại phải chịu thiệt, chỉ một vài sự kiện đương đại được nhắc đến như khủng hoảng kinh tế châu Á (quy lỗi cho Hoa Kỳ, Nhật), thất nghiệp ở Đài Loan (quy lỗi cho Trung Quốc). Ngoài ra, ác cảm còn đến từ va chạm văn hóa hay tín ngưỡng (người Israel gốc Â rập - Đan Mạch, nơi cho đăng biếm họa Mohamad, Pháp Hoa Kỳ) hoặc chính sách can thiệp quân sự/đối ngoại của nước mục tiêu lên một quốc gia khác, có quan hệ nào đó với nước sở tại (người Israel gốc Ả rập - Anh, nước cùng Hoa Kỳ xâm chiếm Iraq), thiếu đạo đức trong hỗ trợ giải quyết khủng hoảng ở nước sở tại (Nhật không giúp các nước châu Á trong khủng hoảng kinh tế châu Â), khác biệt văn hóa - không đồng tình chính sách đối ngoại nói chung đối với nước mục tiêu (Pháp đối với Hoa Kỳ).

Bảng 4: Phân tích một số nghiên cúu tiêu biểu về ác cảm tiêu dùng 2007-2019

\begin{tabular}{|c|c|c|}
\hline Nguồn & $\begin{array}{c}\text { Tình huống - } \\
\text { Nguô̂n gốc }\end{array}$ & Kết quả \\
\hline $\begin{array}{l}1 . \\
\text { Torres and } \\
\text { Gutiérrez } \\
(2007) \text { [3] }\end{array}$ & $\begin{array}{l}\text {-Nước sở tại: Tây Ban Nha } \\
\text {-Nước mục tiêu: Ân Độ, Trung Quốc, Hàn } \\
\text { Quốc. } \\
\text {-Hàng hóa: ô tô với các nhãn hiệu cụ thể từ } \\
3 \text { quốc gia trên. } \\
\text {-Nguồn gốc: không. }\end{array}$ & $\begin{array}{l}\text {-Ác cảm đơn hướng, } 5 \text { mục đo, CFA } \\
\text {-Ác cảm tác động âm đến thẩm định } \\
\text { hàng hóa và ý định mua hàng } \\
\text {-Khó khăn kinh tế (do ngoại nhóm), ảnh } \\
\text { hưởng chuẩn mực (từ nội nhóm) tác } \\
\text { động dương đến ác cảm. Đe dọa kinh tế }\end{array}$ \\
\hline
\end{tabular}




\begin{tabular}{|c|c|c|}
\hline Nguồn & $\begin{array}{c}\text { Tình huống - } \\
\text { Nguồn gốc }\end{array}$ & Kết quả \\
\hline & & $\begin{array}{l}\text { cảm nhận và tuổi là } 2 \text { điều tố của quan } \\
\text { hệ này }\end{array}$ \\
\hline
\end{tabular}

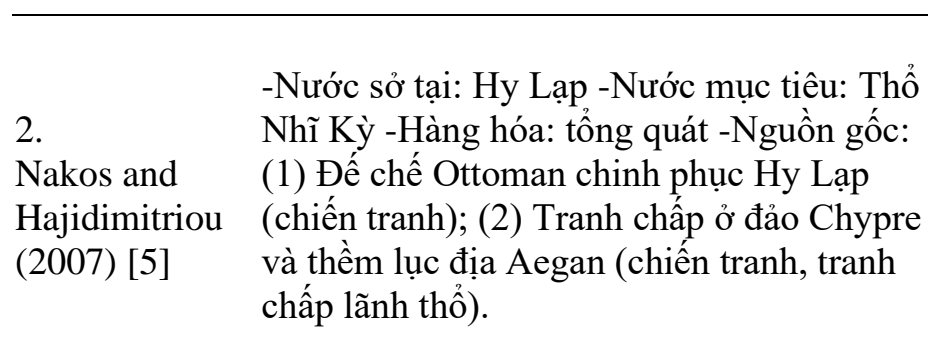

-Nước sở tại: Hàn Quốc (K), Indonesia (I), Thái (T), Malaysia (M), Singapore (S).

$3 . \quad$-Nước mục tiêu: Hoa Kỳ, Nhật

Leong, et al. -Nguồn gốc: các sự kiện lịch sử (chiến (2008) [33] tranh, chính trị, kinh tế), vai trò IMF, Nhật trong cuộc khủng hoảng kinh tế 1990s (kinh tế).

-So với Klein, et al. (1998) [4], thang đo ác cảm suy biến còn 2 thành phần được khảo sát như hai khái niệm độc lập. Đánh giá thang đo bằng EFA -Ác cảm tác động âm đến sã̃n lòng mua, không ảnh hưởng đến thẩm định hàng hóa -Tiền tố đặc trưng cá nhân của ác cảm: Tuổi, năng lực ngoại ngữ

-Ác cảm 2 thành phần đơn hướng (không trình bày kiểm định thang đo); ác cảm kiên định tác động dương đến ác cảm tình huống

-Ác cảm (kiên định, tình huống) tác động âm đến sẵn lòng mua, ác cảm tình huống tác động âm đến thẩm định và cảm xúc đối với hàng hóa -Quy kết hướng ngoại (phạm vi, khả năng kiểm soát) là tiền tố của ác cảm

\begin{tabular}{ll}
\hline 4. & -Nước sở tại: Hoa Kỳ \\
Little, et al. & -Nước mục tiêu: Việt Nam \\
$(2009)[34]$ & -Hàng hóa: \\
\hline & -Nguồn gốc: chiến tranh Việt Nam. \\
\hline
\end{tabular}

-Ác cảm đơn hướng đánh giá bằng Cronbach Alpha $=0,887$.

-Thế hệ càng xa (độ tuổi càng lớn), ác cảm với Việt Nam càng lớn.

-Nước sở tại: Israel -Nước mục tiêu: Anh, Ý -Ác cảm được xác nhận giá trị (có cấu trúc nguyên thủy). đánh giá bằng CFA. -Ác cảm tác động âm đến thẩm định 5. -Nhóm văn hóa: Israel gốc Do thái và gốc Ả hàng hóa và sằn lòng mua.

Rose, et al. rập.

(2009) [35] -Hàng hóa: tổng quát -Nguồn gốc: Ý́ chiếm đóng, Anh tiếp quản Thế chiến II, Anh tham chiến ở Iraq -Người gốc Ả rập có ác cảm với Anh cao hơn, không sẵn lòng mua hàng Anh mạnh hơn người gốc Do Thái. Với Ý, hai nhóm này không có ác cảm và thái độ khác biệt đáng kể

-Nước sở tại: Đài Loan

-Nước mục tiêu: Trung Quốc (lục địa), Nhật

Bản

-Hàng hóa: tổng quát

6. - -Nguồn gốc: Trung Quốc: (1) Cuộc đàn áp

Huang, et al. người Đài Loan của người dân tộc chủ (2010) [36] nghĩa; đối đầu chính trị và quân sự ở thập kỷ 1980, 1990; (2) thất nghiệp Đài Loan tăng do đầu tư vào Trung Quốc; Nhật: (3) -Ác cảm đơn hướng, 3 mục đo, đánh giá bằng $\mathrm{CFA}$

-Ác cảm tác động âm đến niềm tin vào công ty và ý định mua hàng; tác động dương đến tính vị chủng tiêu dùng.

Đài Loan chịu sự chiếm đóng của Nhật từ 1895-1945. 


\begin{tabular}{|c|c|c|}
\hline Nguồn & $\begin{array}{c}\text { Tình huống - } \\
\text { Nguồn gốc }\end{array}$ & Kết quả \\
\hline $\begin{array}{l}7 . \\
\text { Russell and } \\
\text { Russell (2010) } \\
{[6]}\end{array}$ & $\begin{array}{l}\text {-Nước sở tại: Pháp } \\
\text {-Nước mục tiêu: Hoa Kỳ } \\
\text {-Hàng hóa: Nghiên cứu 1: } 14 \text { nhãn hàng từ } \\
\text { thuần Hoa Kỳ đến không phải Hoa Kỳ; } \\
\text { Nghiên cứu 2: } 02 \text { nhãn hàng nước tăng lực } \\
\text { chưa có trên thị trường. } \\
\text {-Nguồn gốc: kinh tế; ngoại giao; quan điểm } \\
\text { chính trị; văn hóa. }\end{array}$ & $\begin{array}{l}\text {-Ác cảm đơn hướng, đánh giá bằng } \\
\text { Cronbach Alpha=0,76. } \\
\text {-Ác cảm tác động âm đến thái độ của } \\
\text { nhãn hiệu với điều tố là liên tưởng quốc } \\
\text { gia-nhãn hàng. } \\
\text {-Nhãn hàng-quốc gia: BCA (đo mức } \\
\text { "Hoa Kỳ" mà khách hàng cảm nhận từ } \\
\text { hàng hóa cụ thể) }\end{array}$ \\
\hline $\begin{array}{l}8 . \\
\text { Maher, et al. } \\
(2010) \text { [37] }\end{array}$ & $\begin{array}{l}\text {-Nước sở tại: Hoa Kỳ } \\
\text {-Nước mục tiêu: Nhật } \\
\text {-Hàng hóa: tổng quát (so với hàng Hoa Kỳ } \\
\text { và Hàn Quốc) } \\
\text {-Nguồn gốc: không (tham khảo NC trước) }\end{array}$ & $\begin{array}{l}\text {-Ác cảm đơn hướng đánh giá bằng CFA. } \\
\text {-Ác cảm không có tác động nào đến } \\
\text { thẩm định hàng hóa và sắn lòng mua. }\end{array}$ \\
\hline $\begin{array}{l}\text { 9. } \\
\text { Maher and } \\
\text { Mady (2010) } \\
{[38]}\end{array}$ & $\begin{array}{l}\text {-Nước sở tại: Kuwait } \\
\text {-Nước mục tiêu: Đan Mạch } \\
\text {-Hàng hóa: tổng quát } \\
\text {-Nguốn gốc: Sự phản đối của khối Ả Rập } \\
\text { trước việc đăng tranh biếm họa về giáo chủ } \\
\text { Mohamad của các bờ báo phương Tây, } \\
\text { khởi đầu là Đan Mạch. }\end{array}$ & $\begin{array}{l}\text {-Ác cảm có cấu trúc bậc I, phản ánh } \\
\text { với } 02 \text { biến quan sát nguyên nhân và } \\
03 \text { biến quan sát biểu hiện. } \\
\text {-Trách nhiệm nhóm tác động dương } \\
\text { đến ác cảm; ác cảm tác động âm đển } \\
\text { sẵn lòng mua và không ảnh hưởng đến } \\
\text { thẩm định hàng hóa }\end{array}$ \\
\hline $\begin{array}{l}\text { 10. Jiménez } \\
\text { and San Martín } \\
\text { (2010) [39] }\end{array}$ & $\begin{array}{l}\text {-Nước sở tại: Tây Ban Nha } \\
\text {-Nước mục tiêu: Hàn Quốc } \\
\text {-Hàng hóa: xe ô tô } \\
\text {-Nguồn gốc: ô tô nhập khẩu từ Hàn Quốc } \\
\text { vào Tây Ban Nha tăng gần gấp đôi trong } 5 \\
\text { năm 2002-2007, chiếm 5,7\% thị phần của } \\
\text { Tây Ban Nha. Nguồn gốc của ác cảm } \\
\text { không được nêu rõ. }\end{array}$ & $\begin{array}{l}\text {-Uy tín liên quan đến xuất xứ hàng hóa } \\
\text { có tác động dương đến niềm tin của } \\
\text { khách hàng; } \\
\text {-Ác cảm có tác động âm đến niềm tin } \\
\text { của khách hàng; } \\
\text {-Ác cảm làm tăng tính vị chủng }\end{array}$ \\
\hline $\begin{array}{l}11 . \\
\text { Hoffmann, et } \\
\text { al. (2011) [40] }\end{array}$ & $\begin{array}{l}\text { Nước sở tại-mục tiêu: (1) Đức-Pháp/Hoa } \\
\text { Kỳ/Nga, (2) Nga-Pháp/Hoa } \\
\text { Kỳ/Đức.N=360 Đức+350 Nga (quota). } \\
\text { Phân tích: PLS, Bootstrap. Kết quả: (1) đạt } \\
\text { giá trị phân biệt và độ tin cậy; (2) Giá trị } \\
\text { tiêu chí: ác cảm quan hệ dương với quốc } \\
\text { gia xuất xứ, tẩy chay, sẵn lòng mua; (3) } \\
\text { mạng nomological: ác cảm quan hệ với vị } \\
\text { chủng tiêu dùng, chủ nghĩa yêu nước và } \\
\text { chử nghĩa quốc tế. }\end{array}$ & $\begin{array}{l}\text { NC 1: khẳng định ác cảm có } 3 \text { nhân tố } \\
\text { (còn } 09 \text { mục đo=03+02+02 ( } 3 \text { thành } \\
\text { phần bậc I) và } 02 \text { ( } 01 \text { thành phần bậc } \\
\text { II) và tác động đến sự tầy chay \& sẵn } \\
\text { lòng mua. } \\
\text { NC 2: kiểm định giá trị cấu trúc (hội } \\
\text { tụ, phân biệt), giá trị tiêu chí và mạng } \\
\text { nomological }\end{array}$ \\
\hline $\begin{array}{l}12 . \\
\text { Richardson } \\
(2012)[41]\end{array}$ & $\begin{array}{l}\text {-Nước sở tại: Hoa Kỳ } \\
\text {-Nước mục tiêu: Nhật } \\
\text {-Hàng hóa: tồng quát } \\
\text {-Nguồn gốc: không (tham khảo NC trước) }\end{array}$ & $\begin{array}{l}\text {-Ác cảm đơn hướng đánh giá bằng } \\
\text { Cronbach Alpha=0,83..0,85 } \\
\text {-Độ tuổi cao, ác cảm cao; nam giới có ác } \\
\text { cảm mạnh hơn nữ. }\end{array}$ \\
\hline $\begin{array}{l}\text { 13. Harmeling, } \\
\text { et al. (2015) } \\
\text { [42] }\end{array}$ & $\begin{array}{l}\text {-Nước sở tại: Trung Quốc và Hoa Kỳ } \\
\text {-Nước mục tiêu: Nhật Bản, Nga } \\
\text {-Hàng hóa: hàng hóa từ Nhật và Nga } \\
\text {-Nguồn gốc: Trung Quốc-Nhật Bản có lịch } \\
\text { sử tranh chấp lâu đời; Hoa Kỳ-Nga có } \\
\text { nhiều tranh chấp trong chính trị, kinh tế. }\end{array}$ & $\begin{array}{l}\text {-Cảm xúc chống đối ảnh hưởng đến } \\
\text { những lời truyền miệng và không mua } \\
\text { hàng của nước mục tiêu. } \\
\text {-Cảm xúc trốn tránh ảnh hưởng đến } \\
\text { thẩm định hàng hóa và không mua } \\
\text { hàng của nước mục tiêu. }\end{array}$ \\
\hline
\end{tabular}




\begin{tabular}{|c|c|c|}
\hline Nguồn & $\begin{array}{c}\text { Tình huống - } \\
\text { Nguồn gốc }\end{array}$ & Kết quả \\
\hline $\begin{array}{l}\text { 14. Fong, et al. } \\
\text { (2015) [43] }\end{array}$ & $\begin{array}{l}\text {-Nước sở tại: Trung Quốc (có nhiều ác } \\
\text { cảm) và Đài Loan (ít ác cảm) } \\
\text {-Nước mục tiêu: Nhật Bản } \\
\text {-Hàng hóa: hàng hóa từ Nhật Bản } \\
\text {-Nguồn gốc: Trung Quốc-Nhật Bản có lịch } \\
\text { sử tranh chấp lâu đời; }\end{array}$ & $\begin{array}{l}\text { - Trung Quốc - quốc gia có nhiều ác } \\
\text { cảm với Nhật: người tiêu dùng có xu } \\
\text { hướng lựa chọn sản phẩm của doanh } \\
\text { nghiệp mang nhiều dấu ấn của nước sở } \\
\text { tại (Trung Quốc) } \\
\text { - Đài Loan - quốc gia có ít ác cảm với } \\
\text { Nhật Bản: người tiêu dùng không bị } \\
\text { ảnh hưởng bởi FDI và hình ảnh quốc } \\
\text { gia nước mục tiêu (Nhật Bản) }\end{array}$ \\
\hline $\begin{array}{l}\text { 15. Marinković } \\
\text { (2017) [32] }\end{array}$ & $\begin{array}{l}\text {-Nước sở tại: Cộng hòa Serbia } \\
\text {-Nước mục tiêu: Châu Âu (EU) } \\
\text {-Hàng hóa: hàng hóa từ Châu Âu nói } \\
\text { chung } \\
\text {-Nguồn gốc: không được nêu rõ }\end{array}$ & $\begin{array}{l}\text { - Ác cảm của người dân Serbia đối với } \\
\text { các nước Châu Âu khiến người tiêu } \\
\text { dùng của quốc gia này mua sản phẩm } \\
\text { quốc nội nhiều hơn }\end{array}$ \\
\hline $\begin{array}{l}\text { 16. Park and } \\
\text { Yoon }(2017) \\
\text { [44] }\end{array}$ & $\begin{array}{l}\text {-Nước sở tại: Hàn Quốc } \\
\text {-Nước mục tiêu: Nhật Bản } \\
\text {-Hàng hóa: (1) nhóm hàng quan trọng chịu } \\
\text { ảnh hưởng nhiều bởi ác cảm (máy ảnh kỹ } \\
\text { thuật số) và (2) nhóm hàng không quan } \\
\text { trọng, ít chịu ảnh hưởng của ác cảm (bút } \\
\text { mực, bút chì) } \\
\text {-Nguồn gốc: sự chiếm đóng của quân Nhật } \\
\text { tại Hàn Quốc trong thế chiến thứ hai. }\end{array}$ & $\begin{array}{l}\text {-Mức độ nhạy cảm với các chuẩn mực } \\
\text { xã hội và ác cảm tiêu dùng ảnh hưởng } \\
\text { cùng chiều đến ác cảm tiêu dùng; } \\
\text { ngược lại, chủ nghĩa thế giới ảnh } \\
\text { hường ngược chiều đến ác cảm tiêu } \\
\text { dùng } \\
\text {-Ác cảm tiêu dùng ảnh hưởng xấu đến } \\
\text { ý định mua hàng quan trọng (máy ảnh } \\
\text { kỹ thuật số), nhưng không có ảnh } \\
\text { hưởng đến nhóm hàng không quan } \\
\text { trọng (bút mực, bút chì) }\end{array}$ \\
\hline $\begin{array}{l}\text { 17. Campo and } \\
\text { Alvarez (2017) } \\
{[45]}\end{array}$ & $\begin{array}{l}\text {-Nước sở tại: Thổ Nhĩ Kỳ } \\
\text {-Nước mục tiêu: Israel } \\
\text {-Hàng hóa: quyết định du lịch đến Israel } \\
\text { của du khách Thổ Nhĩ Kỳ } \\
\text {-Nguồn gốc: tất cả những sự xung đột về } \\
\text { kinh tế, văn hóa, chính trị và quân sự }\end{array}$ & $\begin{array}{l}\text { Ác cảm có ảnh hưởng tiêu cực đến } \\
\text { quyết định du lịch sang nước mục tiêu } \\
\text { thông qua trung gian là tình cảm đối } \\
\text { với quốc gia mục tiêu. }\end{array}$ \\
\hline $\begin{array}{l}\text { 18. Lee, et al. } \\
\text { (2017) [30] }\end{array}$ & $\begin{array}{l}\text {-Nước sở tại: Trung Quốc và Nhật Bản } \\
\text {-Nước mục tiêu: Nhật Bản và Trung Quốc } \\
\text {-Hàng hóa: hàng hóa từ Nhật Bản } \\
\text {-Nguồn gốc: sau thời điểm xảy ra các xung } \\
\text { đột kinh tế, chính trị }\end{array}$ & $\begin{array}{l}\text {-Ác cảm thuộc ký ức thời kỳ và không } \\
\text { ồn định bằng sự vị chủng (thuộc ký ức } \\
\text { tri thức- semantic memory) } \\
\text {-Ác cảm ảnh hưởng đến hành vi tẩy } \\
\text { chay trong suốt thời kỳ xảy ra sự kiện, } \\
\text { nhưng không có ảnh hường sau đó; } \\
\text {-Vị chủng là tiền tố của ác cảm. }\end{array}$ \\
\hline $\begin{array}{l}19 . \\
\text { Muposhi, et al. } \\
\text { (2018) [46] }\end{array}$ & $\begin{array}{l}\text {-Nước sở tại: South Africa } \\
\text {-Nước mục tiêu: Trung Quốc } \\
\text {-Hàng hóa: quần áo } \\
\text {-Nguồn gốc: Ấc cảm kinh tế bắt nguồn từ } \\
\text { thương mại bất đối xứng giữa Nam phi với } \\
\text { Trung Quốc; hàng hóa Trung Quốc bán } \\
\text { vào Nam phi ngày cành nhiều trong } \\
\text { BRICS, một khối bao gồm các nền kinh tế } \\
\text { lớn mới nồi Brazil, Nga (Russia), Ân Độ } \\
\text { (India), Trung Quốc (China) và Nam Phi } \\
\text { (South Africa) }\end{array}$ & $\begin{array}{l}\text {-Thái độ đối với hành hóa là biến trung } \\
\text { gian giữa } 03 \text { yếu tố: ác cảm kinh tế, } \\
\text { tính vị chủng, chủ nghĩa thế giới đối } \\
\text { với ý định mua hàng ngoại; } \\
\text {-Ác cảm kinh tế và tính vị chủng có tác } \\
\text { động âm đến thái độ đối với hàng hóa } \\
\text { và ý định mua hàng ngoại; } \\
\text {-Chủ nghĩa thế giới có tác động dương } \\
\text { đến thái độ đối với hàng hóa và ý định } \\
\text { mua hàng ngoại. }\end{array}$ \\
\hline
\end{tabular}




\begin{tabular}{|c|c|c|}
\hline Nguồn & $\begin{array}{c}\text { Tình huống - } \\
\text { Nguồn gốc }\end{array}$ & Kết quả \\
\hline $\begin{array}{l}\text { 20. Antonetti, } \\
\text { et al. (2019) } \\
\text { [47] }\end{array}$ & $\begin{array}{l}\text {-Nước sở tại: Trung Quốc } \\
\text {-Nước mục tiêu: Nhật Bản } \\
\text {-Hàng hóa: hàng hóa từ Nhật nói chung } \\
\text {-Nguốn gốc: chiến tranh giữa hai quốc gia }\end{array}$ & $\begin{array}{l}\text { Cảm xúc tiêu cực từ ác cảm là nhân tố } \\
\text { then chốt giải thích sự ảnh hưởng của } \\
\text { các cảm đển hành vi tiêu dùng. }\end{array}$ \\
\hline
\end{tabular}

\subsection{Phân loại, tiếp cận khái niệm và cấu trúc đo lường}

Theo quan điểm phân loại $2 \times 2$ của Jung, et al. (2002) [23], có thể thấy hầu hết các nghiên cứu tập trung cho ác cảm cấp quốc gia, chỉ có một nghiên cứu đề cập đến cấp cá nhân [38]. Trong khi ác cảm do chiến tranh có cả hai loại phân biệt rõ rệt: kiên định và tình huống thì ác cảm do kinh tế có sự chồng lấn kiên định và tình huống; các nguyên nhân khác hầu hết là tình huống.

Tuy nhiên, phân loại $2 \times 2$ này đã không được sử dụng như thứ nguyên chính để các định các thành phần khái niệm. Hầu hết (16/20) nghiên cứu sử dụng hoặc vận dụng triệt để cấu trúc loại phản ánh và thang đo mà Klein et al.[4] đưa ra theo 04 dạng sau:

- Ác cảm có cấu trúc bậc I, đơn hướng, chỉ gồm 3 đến 5 biến quan sát thuần cảm xúc (không thích, căm ghét), không đề cập nguyên nhân [3, 30, 36, 37, 42, 47],

- Ác cảm có cấu trúc bậc I, đơn hướng, gồm 9 đến 12 biến quan sát bao gồm cả nguyên nhân (chiến tranh, kinh tế) và thuần cảm xúc $[6,34,41]$,

- $\quad$ Ác cảm có cấu trúc bậc I, đa huoóng, gồm 2 thành phần đơn hướng: chiến tranh, kinh tế [5, 33]. Hai thành phần này được khảo sát độc lập nhau trong quan hệ với các tiền tố và hệ quả.

- Ác cảm có cấu trúc bậc II, đa hướng như thang gốc của Klein, et al. (1998) [4] và Rose, et al. (2009) [35], có bổ sung thêm thứ nguyên [45].

Mặc dù giới thiệu các tình huống, nguồn gốc dẫn đến ác cảm nhưng các nghiên cứu trên đã không đặt trọng tâm vào xác định nguyên nhân ác cảm và đánh giá cấu trúc khái niệm. Có thể thấy gần như các nguyên nhân, thành phần ác cảm được người nghiên cứu xác định trước qua thang đo sử dụng chủ yếu từ nghiên cứu trước, nêu hầu như không có nghiên cứu định tính (phỏng vấn, thảo luận) nào được tiến hành như đề xuất của Riefler and Diamantopoulos (2007) [25] trước khi điều tra và phân tích định lượng.

Các nghiên cứu khảo sát ác cảm như khái niệm loại tạo sinh - MIMIC (đa mục đo, đa nguyên nhân) với 2 dạng sau.

- $\quad$ Ác cảm có cấu trúc bậc $I$, với 3 biến quan sát biểu hiện và chỉ 01 biến quan sát nguyên nhân có giá trị [38], tình huống cụ thể trong nghiên cứu là người tiêu dùng Kuwait và hàng hóa Đan Mạch, quốc gia cho phép đăng tải biếm họa tiên tri Mohamad trên báo chí.

- $\quad$ Ác cảm có cấu trúc bậc II - 2 biến quan sát, với 3 khái niệm bậc I loại phản ánh: (1) đe dọa cảm nhận -3 biến quan sát, (2) thái độ chính trị đối lập -2 biến quan sát và (3) trải nghiệm cá nhân tiêu cực -2 biến quan sát [40]. Trong nghiên cứu này, các nhà nghiên cứu mong muốn đưa ra một thang đo xuyên quốc gia (cross-national), nên triển khai ở nhiều nước sở tại (Đức, Ukraina, Nga), mỗi nước sở tại được đo lường ác cảm với 2 đến 3 nước mục tiêu (Hoa Kỳ, Pháp, Nga. Đức). Nghiên cứu của Campo and Alvarez (2017) [45] sử dụng mô hình đo lường khái niệm ác cảm theo cấu trúc bậc II 2 biến quan sát, với 6 khái niệm bậc I loại phản ánh: (1) kinh tế-4 biến quan sát, (2) con người - 4 biến quan sát, (3) chính trị- 5 biến quan sát, (4) tôn giáo - 2 biến quan sát, (5) lịch sử - 2 biến quan sát và (6) quân sự - 3 biến quan sát.

Với hai mục tiêu khác nhau, hai nghiên cứu trên có cách tiếp cận khái niệm ác cảm là như nhau theo 3 bước của nghiên cứu định tính (phỏng vấn, thảo luận) như đề xuất của Riefler and Diamantopoulos [25].

\section{5 Đánh giá khái niệm}

Ngoại trừ 03 nghiên cứu dùng độ tin cậy Cronbach Alpha hoặc $\mathrm{EFA}$ và 01 nghiên cứu dùng phương pháp định tính kết hợp phân tích ANOVA/ANCOVA, 16 nghiên cứu còn lại đều dùng CFA để kiểm định thang đo và cấu trúc của ác cảm. Kết quả cho thấy dù có cấu trúc khác nhau, ác cảm phân biệt rõ rệt với 
tính vị chủng tiêu dùng về nội dung và nhiều tiền tố. Về hệ quả, hầu hết nghiên cứu khẳng định ác cảm làm giảm ý định/sự sẵn lòng mua hàng có xuất xứ hoặc mang đặc trưng quốc gia mục tiêu. Một số nghiên cứu khẳng định ác cảm tác động tiêu cực đến thẩm định hàng hóa - ngược với lý thuyết và chứng minh của Klein và các cộng sự.

Bảng 5: Đánh giá khái niệm ác cảm tiêu dùng của 20 nghiên cứu tiêu biểu (2007-2019)

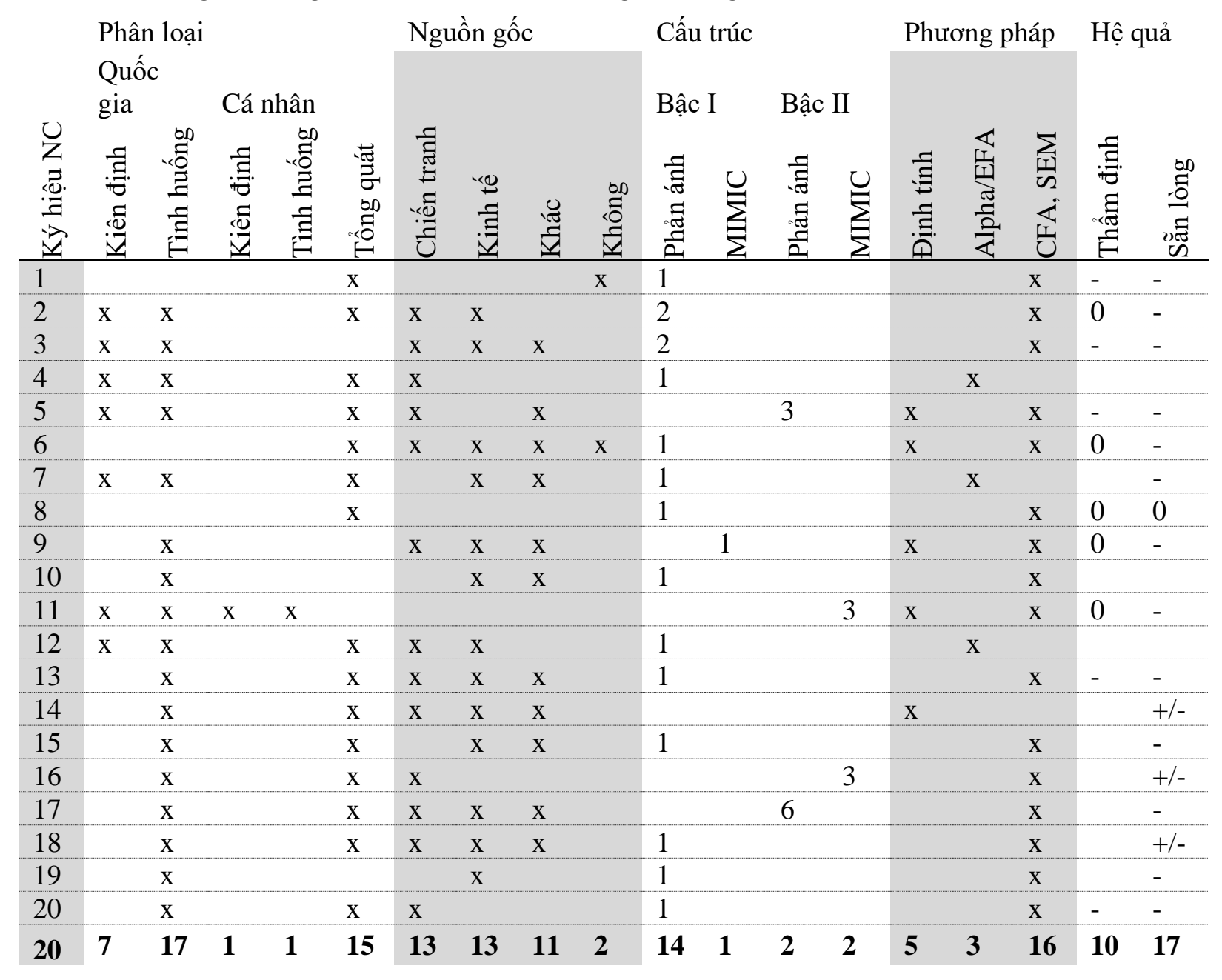

Nguồn: Tổng hợp tù̀ 20 nghiên cứu tiêu biểu (2007-2019)

Ghi chú:

$\begin{array}{ll}\text {-Ký hiệu NC: } & \text { số ký hiệu=số thứ tư cột Nguồn ở Bảng } 4 \\ \text {-Cấu trúc: } & \text { 1, 2, } 3 \text { là số thành phần đơn huoóng bậc I } \\ \text {-Hệ quả: } & \text { 0: không tác động, - : tác động âm }\end{array}$

Qua các phân tích 20 nghiên cứu trên (tổng kết tóm tắt ở Bảng 4), có thể đưa ra các nhận xét, đánh giá sau đây:

- $\quad$ Ác cảm là nhân tố phổ biến, cùng với tín hiệu chất lượng và tính vị chủng tiêu dùng, ác cảm có vai trò quan trọng trong hình thành thái độ, điều chỉnh hành vi tiêu dùng hàng ngoại của khách hàng. Các tiền tố của ác cảm bao gồm: địa vị kinh tế-xã hội, tâm lý đồ và một số yếu tố nhân khẩu học [28] (xem Bảng 2). Các tiền tố, điều tố ác cảm cũng được xác định và làm rõ thêm trong các nghiên cứu sau này.

- Nguồn gốc ác cảm đã mở rộng hơn định nghĩa ban đầu của Klein, et al. (1998) [4] và tổng lược của Riefler and Diamantopoulos (2007) [25], ác cảm có thể đến từ sự cố va chạm giá trị tinh thần tôn 
giáo [38], khác biệt văn hóa nội nhóm - ngoại nhóm, khác biệt quan điểm chính trị $[6,40]$ hay sự can thiệp (mà người nước sở tại cho là sai trái) của nước mục tiêu vào nước khác [35], và những xung đột trong lợi ích kinh tế [46]. Ác cảm được cho là có tác động đến niềm tin vào sản phẩm có xuất xứ từ quốc gia mục tiêu; đồng thời làm tăng tính vị chủng vì ác cảm làm tăng sự đoàn kết dẫn đến hành vì bảo vệ nội bộ [39]. Lưu ý rằng, ác cảm có thể hình thành mà không cần phải có một hệ quả hiện thực hay tiềm năng đến cá nhân hay quốc gia sở tại.

- Mặc dù dẫn nguyên nhân của ác cảm, hầu hết nghiên cứu lại cho rằng ác cảm có cấu trúc phản ánh với nhiều hình thái khác nhau (chỉ có 2 nghiên cứu tiếp cận ác cảm theo cấu trúc MIMIC). Mặt khác, các nghiên cứu này gần như ấn định sẵn nguồn gốc, do đó, không tiến hành nghiên cứu định tính để khám phá nguyên nhân để phát triển thang đo theo khuyến cáo của Riefler and Diamantopoulos [25]. Cảm xúc đổi với một quốc gia mục tiêu là có thể tổng quát hóa để lập thang đo xuyên quốc gia, nhưng, như chính Klein, et al. (1998) [4] trình bày, nguồn gốc của nó đến từ các sự kiện, biến cố cụ thể trong lịch sử hoặc đương đại. Như vậy, việc trộn lẫn nguyên nhân và kết quả để thành một khái niệm tiềm ẩn bộc lộ sự không phù hợp lớn nhất về lý thuyết. Điều này dẫn đến giá trị khái niệm chưa cao. Đáng chú ý là không có nghiên cứu nào trình bày đánh giá so sánh giữa hai mô hình cấu trúc phản ánh và tạo sinh của khái niệm ác cảm.

\section{KẾT LUẬN VÀ ĐỀ XUẤT HƯớNG NGHIÊN CÚU}

Ác cảm là một khái niệm tâm lý xã hội, được Klein, et al. (1998) [4] giới thiệu và đưa vào mô hình hành vi tiêu dùng hàng nước ngoài. Ác cảm được định nghĩa là cảm xúc tiêu cực (không thích, căm ghét) của cá nhân đối với một quốc gia mục tiêu, cảm xúc đó được hình thành từ các sự kiện quân sự, kinh tế, đối ngoại... giữa hai nước trong lịch sử hoặc đương đại.

Tiếp sau khởi đầu của Klein, et al. (1998) [4], nhiều nghiên cứu ác cảm được thực hiện. Trong đó, đáng chú ý là phân loại ác cảm thành 4 loại (2x2) theo hai thứ nguyên: (1) phạm vi: cá nhân/quốc gia, (2) nguồn: kiên định/tình huống và tổng lược của Riefler and Diamantopoulos [25] phê phán sự không tương hợp giữa định nghĩa khái niệm và cấu trúc đo lường của ác cảm. Cho rằng khái niệm này có cấu trúc tạo sinh dạng MIMIC, Riefler and Diamantopoulos [25] đề xuất trình tự ba bước tiếp cận để xây dựng thang đo.

Kết quả tổng lược 20 nghiên cứu về ác cảm kể từ 2007 đến 2019 (Bảng 4) cho thấy nguồn gốc phát sinh ác cảm càng được mở rộng hơn và ác cảm đóng vai trò phổ biến, quan trọng trong mô hình tiêu dùng hàng ngoại. Tuy nhiển, cách tiểp cận chủ quan (ấn định trước nguyên nhân), xem ác cảm có cấu trúc phản ánh vẫn chiếm đa số và chưa có nghiên cứu nào kiểm định so sánh hai cấu trúc.

Như đã trình bày, khái niệm ác cảm đối với một quốc gia của người tiêu dùng là hiện tượng phổ biến toàn cầu. Ác cảm này được tạo sinh từ các sự kiện, biên cố đương đại hoặc tích lũy qua lịch sử ở phạm vi quốc gia hoặc trải nghiệm của chính cá nhân. Các sự kiện, biến cố đó trải rộng từ chiến tranh, quan hệ thương mại - kinh tế cho đến mâu thuẫn quan điểm chính trị, quân sự, đường lối đối ngoại, khác biệt văn hóa hay va chạm tín ngưỡng. Hệ quả xấu trực tiếp hay tiềm năng của các biến cố này tác động không nhất thiết phải tác động trực tiếp đến chính cá nhân, quốc gia sở tại.

Về cấu trúc đo lường, trong đa số nghiên cứu được tổng lược, khái niệm ác cảm được chỉ định là khái niệm ẩn, dạng phản ánh - nhưng cấu trúc chi tiết chưa nhất quán (có thể đơn hướng hay đa hướng, bậc I hay bậc II, xem Hình 3). Điều này - như Riefler and Diamantopoulos [25] đã chỉ ra - bộc lộ sự không tương hợp giữa cấu trúc và định nghĩa lý thuyết. Ngoài ra cũng chưa có nghiên cứu chỉ ra sự phù hơn của cấu trúc đo lường nào: phản ánh hay tạo sinh. Vậy, câu hỏi nghiên cưu thư nhất đặt ra là, dạng cấu trúc nào của khái niệm ác cảm là có giá trị cao hơn. Cần nghiên cứu thêm về dạng cấu trúc của khái niệm với mục tiêu là xác định dạng cấu trúc phù hợp để đo lường khái niệm ác tiêu dùng.

Các nghiên cứu trước đây tập trung vào ác cảm mà chưa đặt ra vấn đề thiện cảm. Trên thực tế, một quốc gia không chỉ có xung đột, bất đồng, mâu thuẫn mà còn có thể có hợp tác, cộng tác, liên minh, tương trợ với một quốc gia khác. Cảm xúc tích cực, nếu có, có thể được gọi là thiện cảm hay quan hệ thân thiện (amity). Kết quả tra cứu trên Google Scholar với từ khóa "consumer amity" và "amity" cho thấy có ít nghiên cứu về khái niệm này trong lĩnh vực kinh doanh, Marketing. Đơn cử nghiên cứu của Ouellet (2006) [48] nghiên cứu sự ảnh hưởng của thiện cảm quốc gia, một thái độ tích cực của người tiêu dùng đối với quốc gia mục tiêu, ảnh hưởng đến hành vi mua hàng ngoại tại Hoa Kỳ. Ngoài ra, Langbein and Bess (2002) [49] 
sử dụng thuật ngữ amity để diễn tả mối quan hệ thân thiện tích cực giữa các nhóm học sinh trong trường học. Vậy, câu hỏi nghiên cứu thứ hai là, các sụ kiện quân sụ, chính trị, văn hóa, ngoại giao, kinh tế có liên quan đến một quốc gia muc tiêu có thể tạo ra thiện cảm của nguoời tiêu dùng với quốc gia đó hay không. Thậm chí, một hiện tượng rất phổ biến trong quan hệ quốc tế là, hai quốc gia có thể vừa cộng tác vừa tranh chấp. Khi đó, cảm xúc của người tiêu dùng đối với quốc gia muc tiêu sẽ nhu thế nào, đó là câu hỏi nghiên cứu thứ $b a$. Các nghiên cứu tiếp theo có thể nhắm đến mục tiêu đo lường, đánh giá tình cảm, thiện cảm và/hoặc ác cảm, đối với một quốc gia và sự ảnh hưởng của tình cảm đến quyết định mua hàng của người tiêu dùng.

Việt Nam là một quốc gia đang phát triển, có nhiều cuộc chiến tranh, đấu tranh vũ trang, chịu sự chiếm đóng của nhiều nước như Trung Quốc, Pháp, Hoa Kỳ, Nhật, Hàn Quốc... nhưng cũng có mối quan hệ hợp tác, nhận viện trợ kinh tế hoặc quân sự với các quốc gia này. Các nghiên cứu về ác cảm trong hành vi tiêu dùng ở Việt Nam gần như chưa có. Vậy, câu hỏi nghiên cưu thứ tu là, người Việt Nam có ác cảm với quốc gia nào, tại sao, mức độ bao nhiêu và có ảnh hưởng đến thái độ đối với hàng hóa quốc gia đó hay không. Các nghiên cứu về ác cảm tiêu dùng của người Việt sẽ làm rõ những đặc điểm của người tiêu dùng Việt trên phương diện tình cảm đối với một số quốc gia mục tiêu và phân tích sự ảnh hưởng của tình cảm đối với một quốc gia đến quyết định mua hàng của quốc gia đó.

Nghiên cứu của Jiménez and San Martín (2010) [39] cho thấy ác cảm làm tăng tính vị chủng. Chủ nghĩa thế giới có tác động tích cực đến thái độ đối với hàng hóa và ý định mua hàng ngoại [46]. Riefler and Diamantopoulos (2007) [25] cho rằng chủ nghĩa thế giới làm suy yếu tính vị chủng. Lịch sử chống ngoại xâm của Việt Nam khiến người Việt đoàn kêt, giàu lòng yêu nước và tự hào dân tộc [50]. Việt Nam giành được độc lập từ năm 1945 và thống nhất đất nước từ 1975; kinh tế xã hội Việt Nam và thế giới có nhiều thay đổi manh mẽ trong những thập niên gần đây, đặc biệt là sự toàn cầu hóa. Trước những thay đổi như vậy, câu hỏi thứ năm được đặt ra là, mưc độ ủng hộ chủ nghĩa thế giới, sụ vị chủng và ác cảm tiêu dùng cưa người Việt với một số quốc gia trên thế giới của người tiêu dùng Việt Nam đã thay đổi nhu thế nào qua các thế hệ. Những nghiên cứu tiếp theo có thể chọn mục tiêu phân tích sự khác biệt giữa các nhóm người tiêu dùng theo độ tuổi về mức độ ủng hộ chủ nghĩa thế giới, sự vị chủng và ác cảm tiêu dùng.

Ngoài ra, theo đề xuất của Shoham, et al. (2016) [26], cần kiểm tra tác động tổng hợp của các yếu tố ác cảm và sự vị chủng đến các biến marketing như đánh giá chất lượng sản phẩm, sự sẵn lòng mua và thực mua của người tiêu dùng. Kết quả tổng lược của các tác giả này cho thấy sự ảnh hưởng chung của ác cảm và sự vị chủng đến sự sẵn lòng mua mạnh hơn (tương ứng là $-0,29$ và $-0,34)$. Trong khi đó, nếu xem xét riêng lẻ, sự tác động của từng yếu tố đển sự sẵn lòng mua tương ứng là $-0,23$ và $-0,30$. Bên cạnh đó, chủ nghĩa thế giới cũng có tác động đến ý định mua hàng ngoại [46]. Từ đó câu hỏi thứ sáu được đặt ra là, chủ nghĩa thế giới, sụ vị chủng và ác cảm của người tiêu dùng tác động nhu thế nào (theo mồ hình nào) đến các biến marketing (thẩm định hàng hóa, sự sắn lòng mua và thực mua của người tiêu dùng). Cần có thêm những nghiên cứu với mục tiêu xác định mô hình phù hợp đánh giá tác động của chủ nghĩa thế giới, sự vị chủng và ác cảm của người tiêu dùng đến các biến marketing. 

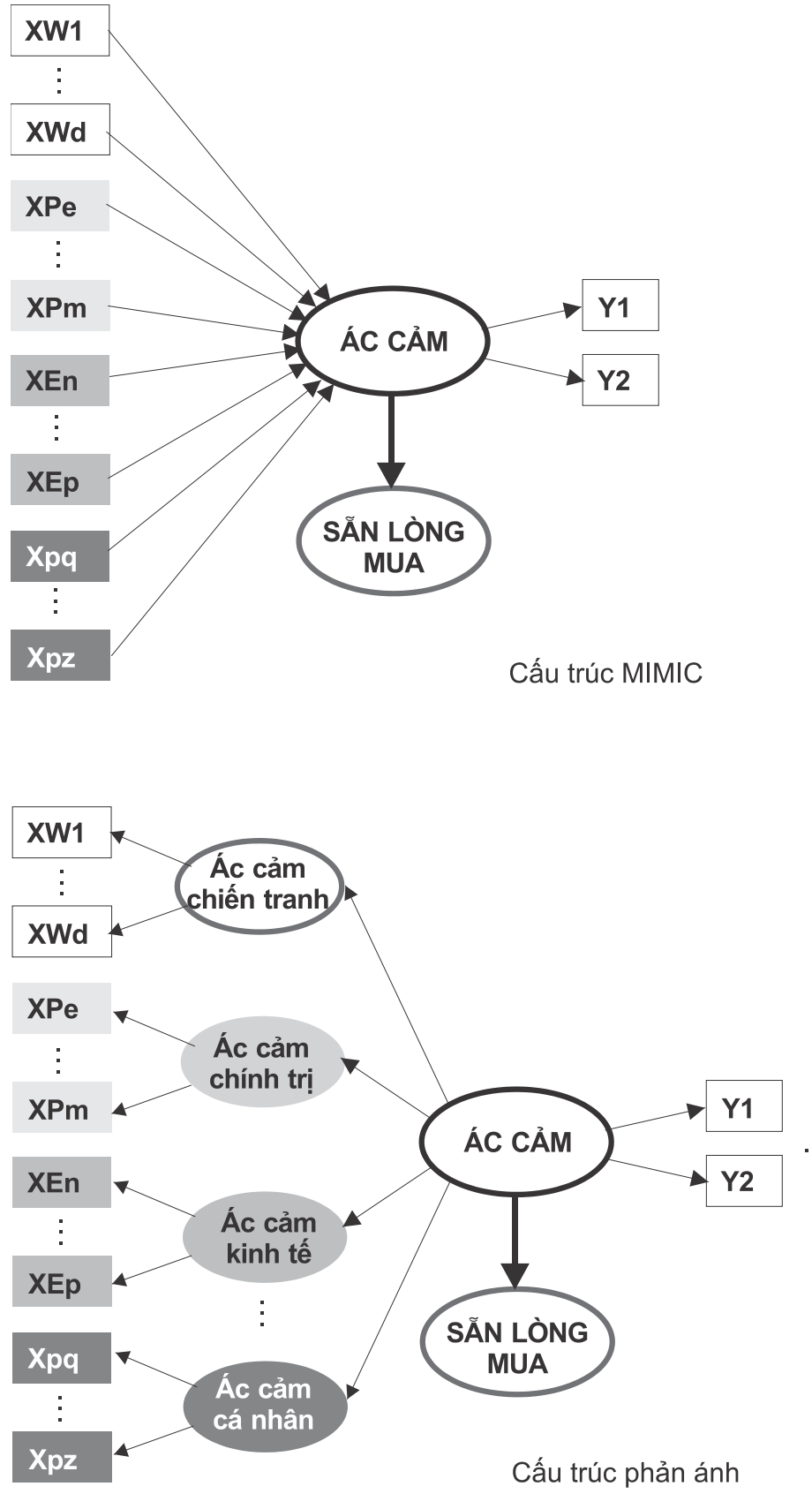

Hình 3: Mô hình kiểm định ác cảm dạng phản ánh và tạo sinh theo Riefler and Diamantopoulos (2007) [25]

\section{TÀI LIỆU THAM KHẢO}

[1] J. A. Frankel, "Globalization of the Economy," National Bureau of Economic Research, Working Paper No. 78582000, Available: https://www.nber.org/papers/w7858.pdf.

[2] K. E. Bang and T. Markeset, "Identifying the drivers of economic globalization and the effects on companies' competitive situation," in IFIP International Conference on Advances in Production Management Systems, 2011, pp. 233-241: Springer.

[3] N. H. J. Torres and S. S. M. Gutiérrez, "The purchase of foreign products: the role of firm's country-of-origin reputation, consumer ethnocentrism, animosity and trust," Tendencias en Dirección de Empresas, 13/07. Consultado el 19 de mayo de 2010, desde, Available: http://www.eco.uva.es/empresa/uploads/dt_13_07.pdf 
[4] J. G. Klein, R. Ettenson, and M. D. Morris, "The Animosity Model of Foreign Product Purchase: An Empirical Test in the People's Republic of China," The Journal of Marketing, vol. 62, no. 1, pp. 89-100, 1998.

[5] G. E. Nakos and Y. A. Hajidimitriou, "The Impact of National Animosity on Consumer Purchases: The Modifying Factor of Personal Characteristics," Journal of International Consumer Marketing, vol. 19, no. 3, pp. 53-72, 2007.

[6] C. A. Russell and D. W. Russell, "Guilty by stereotypic association: Country animosity and brand prejudice and discrimination," Marketing Letters, vol. 21, no. 4, pp. 413-425, 2010.

[7] P. W. J. Verlegh and J.-B. E. M. Steenkamp, "A review and meta-analysis of country-of-origin research," Journal of Economic Psychology, vol. 20, no. 5, pp. 521-546, 1999.

[8] R. Pappu, P. G. Quester, and R. W. Cooksey, "Country image and consumer-based brand equity: relationships and implications for international marketing," Journal of International Business Studies, vol. 38, no. 5, pp. 726745, 2007.

[9] Danh Văn, "Trung Quốc tẩy chay hàng Pháp (theo BusinessWeek và Newsweek)," in Thời báo Kinh tế Sài Gòn, ed. Thành phố Hồ Chí Minh, 2008.

[10] Phương Thanh. (2003). Phong trào tẩy chay hàng Hoa Kỳ lan rộng (theo Reuters). Available: http://vnn.vietnamnet.vn/kinhte/toancanh/2003/3/6417/

[11] Lê Thị Hồng Loan. (2016). Tại sao người Ân Độ muốn tẩy chay hàng Trung Quốc? Available: http://nghiencuuquocte.org/2016/11/21/an-do-tay-chay-hang-trung-quoc/

[12] Linh Nguyễn. (2016). Người dân Ân Độ đồng loạt tẩy chay hàng Trung Quốc. Available: http://soha.vn/nguoidan-an-do-dong-loat-tay-chay-hang-trung-quoc-20161011111209986rf20161011111209986.htm

[13] An Huy. (2017). Doanh nghiệp Hàn Quốc khốn đốn vì bị Trung Quốc tẩy chay. Available: http://vneconomy.vn/the-gioi/doanh-nghiep-han-quoc-khon-don-vi-bi-trung-quoc-tay-chay-

20170821051228846.htm

[14] Minh Khuê. (2018). Người tiêu dùng Canada 'tẩy chay' hàng hóa Mỹ để phản đối Tổng thống Trump. Available: http://vietnamfinance.vn/nguoi-tieu-dung-canada-tay-chay-hang-hoa-my-de-phan-doi-tong-thong-trump20180504224208229.htm

[15] Trung Mến. (2018). Cộng đồng mạng Trung Quốc bắt đầu kêu gọi tẩy chay hàng Mỹ. Available: https://bizlive.vn/the-gioi/cong-dong-mang-trung-quoc-bat-dau-keu-goi-tay-chay-hang-my-3443757.html

[16] Thống kê Hải quan. (2018). Tình hình xuất khẩu, nhập khẩu hàng hóa của Việt Nam tháng 12 và 12 tháng năm 2017. Available: http://www.customs.gov.vn/lists/tinhoatdong/ViewDetails.aspx

[17] Nguyễn Tài Tiến. (2012). Siêu thị chê hoa quả nội. Available: http://vef.vn/2012-03-09-sieu-thi-che-hoa-quanoi

[18] Quang Thuần, "Khốc liệt thị trường cà phê," in Thanh Niên, ed, 2012.

[19] Thành Vinh, "Đồ chơi trẻ em: Bao giờ hàng nội "lên ngôi"?," in Thời báo Doanh nhân, ed, 2012.

[20] Việt Hoàng, "Bánh kẹo Tết Nhâm Thìn: Hàng nội chiếm thị phần áp đảo VietNamNet," in Vietnamnet, ed, 2012.

[21] Võ Thị Quý and Cao Quốc Việt, "Kết hợp phương pháp netnography và lý thuyết nền (grounded theory) trong nghiên cứu định tính để khám phá mô hình hành vi tẩy chay của người tiêu dùng," Tạp chí Phát triển Khoa học và Công nghệ, vol. 18, no. 4Q, pp. 16-24, 2015.

[22] Đặng Thị Kim Thoa, "Nghiên cứu các nhân tố ảnh hưởng đến sự sẵn sàng mua hàng may mặc nội địa của người tiêu dùng Việt Nam ở các thành phố," Luận án Tiến sĩ Kinh tế, Đại học Kinh tế Quốc dân, Thành phố Hà Nội, 2017.

[23] K. Jung, S. H. Ang, S. M. Leong, S. J. Tan, C. Pornpitakpan, and A. K. Kau, "A Typology of Animosity and its Cross-National Validation," Journal of Cross-Cultural Psychology, vol. 33, no. 6, pp. 525-539, 2002. 
[24] S. H. Ang, K. Jung, A. K. Kau, S. M. Leong, C. Pornpitakpan, and e. J. Tan, "Animosity towards economic giants: what the little guys think," The Journal of Consumer Marketing, vol. 21, no. 2/3, pp. 190-207. , 2004.

[25] P. Riefler and A. Diamantopoulos, "Consumer animosity: a literature review and a reconsideration of its measurement," International Marketing Review, vol. 24, no. 1, pp. 87-119, 2007.

[26] A. Shoham, Y. Gavish, and G. M. Rose, "Consequences of consumer animosity: A meta-analytic integration," Journal of International Consumer Marketing, vol. 28, no. 3, pp. 185-200, 2016.

[27] J. G. Klein, "Us versus them, or us versus everyone? Delineating consumer aversion to foreign goods," Journal of International Business Studies, vol. 33, no. 2, pp. 345-363, 2002.

[28] J. G. Klein and R. Ettenson, "Consumer animosity and consumer ethnocentrism: An analysis of unique antecedents," Journal of International Consumer Marketing, vol. 11, no. 4, pp. 5-24., 1999.

[29] R. Ettenson and J. G. Klein, "The fallout from French nuclear testing in the South Pacific: A longitudinal study of consumer boycotts," International Marketing Review, vol. 22, no. 2, pp. 199-224, 2005.

[30] R. Lee, K. T. Lee, and J. Li, "A memory theory perspective of consumer ethnocentrism and animosity," European Journal of Marketing, vol. 51, no. 7/8, pp. 1266-1285, 2017.

[31] S. Sharma, T. A. Shimp, and J. Shin, "Consumer Ethnocentrism: A Test of Antecedents and Moderators," Journal of the Academy of Marketing Science, vol. 23, no. 1, pp. 26-37, 1995.

[32] V. Marinković, "Effects of the Republic of Serbia's citizens' patriotism and animosity towards the European Union on consumer ethnocentrism," Ekonomski horizonti, vol. 19, no. 1, pp. 3-15, 2017.

[33] S. M. Leong et al., "Understanding consumer animosity in an international crisis: nature, antecedents,and consequences," Journal of International Business Studies, vol. 39, pp. 996-1009, 2008.

[34] J. P. Little, E. Little, and K. C. Cox, "U.S. Consumer Animosity Towards Vietnam: A Comparison Of Generations," Journal of Applied Business Research, vol. 25, no. 6, pp. 13-22, 2009.

[35] M. Rose, G. Rose, and A. Shoham, "The impact of consumer animosity on attitudes towards foreign goods: a study of Jewish and Arab Israelis," The Journal of Consumer Marketing, vol. 26, no. 5, pp. 330-339, 2009.

[36] Y.-A. Huang, I. Phau, and C. Lin, "Consumer animosity, economic hardship, and normative influence: How do they affect consumers' purchase intention?," European Journal of Marketing, vol. 44, no. 7/8, pp. 909-937, 2010.

[37] A. A. Maher, P. Clark, and A. Maher, "International consumer admiration and the persistence of animosity," The Journal of Consumer Marketing, vol. 27, no. 5, pp. 414-424. , 2010.

[38] A. A. Maher and S. Mady, "Animosity, subjective norms, and anticipated emotions during an international crisis," International Marketing Review, vol. 27, no. 6, pp. 630-651, 2010.

[39] N. H. Jiménez and S. San Martín, "The role of country-of-origin, ethnocentrism and animosity in promoting consumer trust. The moderating role of familiarity," International Business Review, vol. 19, no. 1, pp. 34-45, 2010.

[40] S. Hoffmann, R. Mai, and M. Smirnova, "Development and validation of a cross-nationally stable scale of consumer animosity," Journal of Marketing Theory and Practice, vol. 19, no. 2, pp. 235-252, 2011.

[41] C. W. Richardson, "Consumer Demographics as Antecedents in the Animosity Model of Foreign Product Purchase," International Journal of Business and Social Science, vol. 3, no. 4, pp. 13-21, 2012.

[42] C. M. Harmeling, P. Magnusson, and N. Singh, "Beyond anger: A deeper look at consumer animosity," Journal of International Business Studies, vol. 46, no. 6, pp. 676-693, 2015.

[43] C.-M. Fong, C.-L. Lee, and Y. Du, "Consumer animosity and foreign direct investment: An investigation of consumer responses," International Business Review, vol. 24, no. 1, pp. 23-32, 2015.

[44] J. E. Park and S.-J. Yoon, "Antecedents of consumer animosity and the role of product involvement on purchase intentions," American Journal of Business, vol. 32, no. 1, pp. 42-57, 2017. 
[45] S. Campo and M. D. Alvarez, "Consumer Animosity and Affective Country Image," in Co-Creation and WellBeing in TourismCham: Springer, 2017, pp. 119-131.

[46] A. Muposhi, M. Dhurup, and R. M. Shamhuyenhanzva, "Underlying correlates of consumers' attitudes towards Chinese apparel and relationship with purchase intention in South Africa," TD: The Journal for Transdisciplinary Research in Southern Africa, vol. 14, no. 1, pp. 1-10, 2018.

[47] P. Antonetti, D. Manika, and C. Katsikeas, "Why consumer animosity reduces product quality perceptions: The role of extreme emotions in international crises," International Business Review, 2019.

[48] J.-F. Ouellet, "The Consumer Amity Influence on Foreign Product Purchase in the US," ACR Asia-Pacific Advances, 2006.

[49] L. Langbein and R. Bess, "Sports in school: Source of amity or antipathy?," Social Science Quarterly, vol. 83, no. 2, pp. 436-454, 2002.

[50] Lê Huy Tuynh. (2018) Đặc trưng giá trị văn hóa giữ nước truyền thống Việt Nam. Văn hóa Nghệ thuật.

Ngày nhận bài: 20/08/2019

Ngày chấp nhận đăng: 28/11/2019 